العـدد الرابع والأربعون

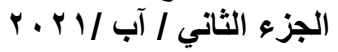

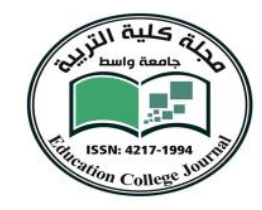

\title{
مستوى تطبيق الادارة الكترونية في كليات الجامعة المستصرية \\ من وجهة نظر المعاونين ورؤساء الأقسام العلمية
}

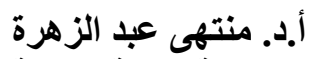

الجامعة المستنصرية / كلية التربية

muntaha51@yahoo.com

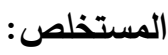

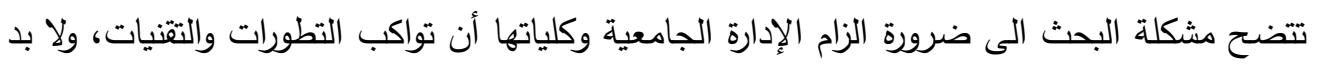

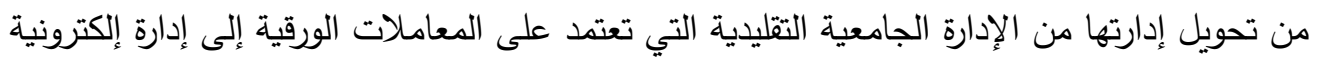

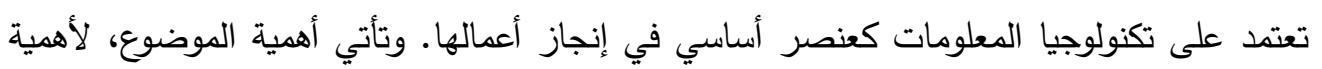
الإدارة الإلكترونية وضرورة تطبيقها في إدارات مؤسسات التعليم العالي.

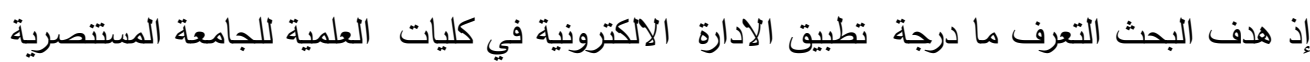

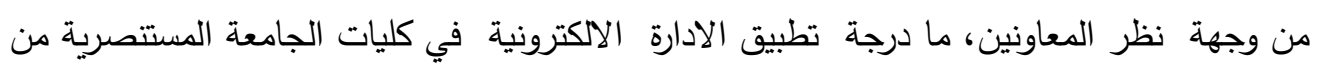
وجهة نظر رؤساء الأقسام العلمية .

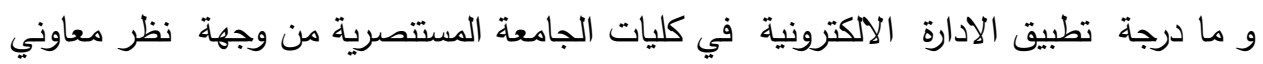

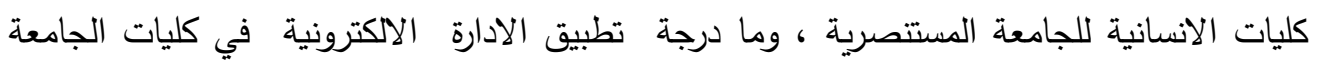

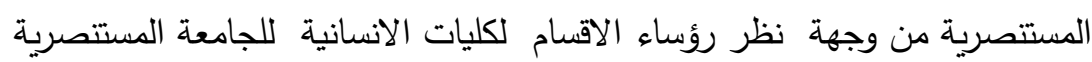

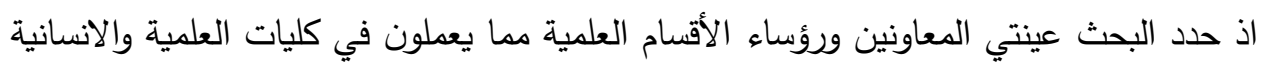

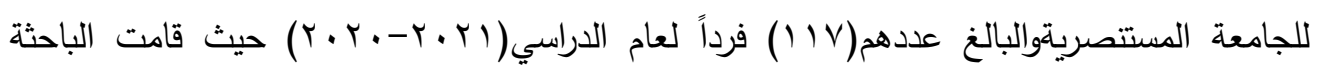

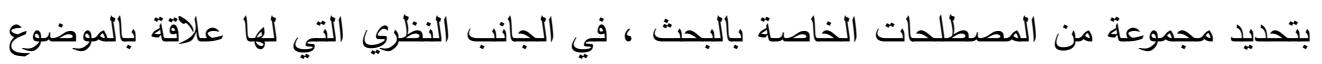

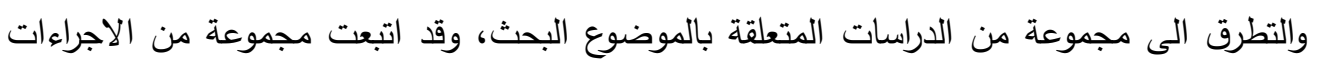

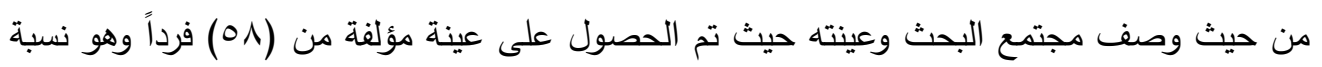

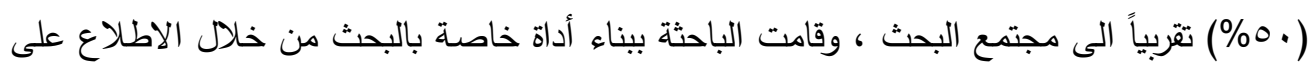

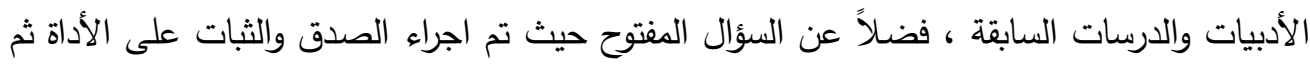

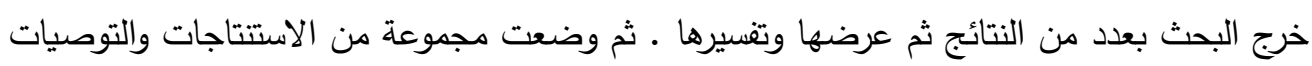

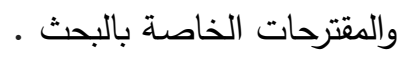
الكلمات المفتاحية : مستوى ،الادارة الكترونية ، كليات، الجامعة المستنصرية ، المعاونين، رؤساء الاقسام العلمية. 

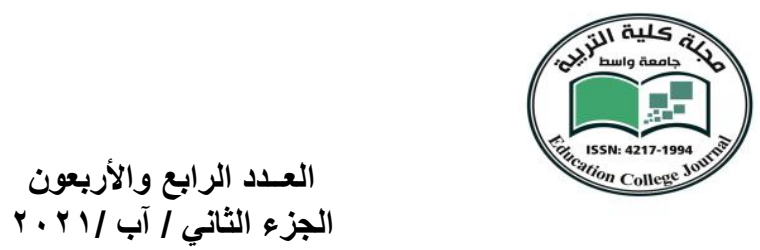

The level of electronic administration application in the colleges of AlMustansiriya University from the point of view of the assistants and heads of scientific departments

. Dr. Muntaha Abuul -Zahra Al-Azzawi Mustansirya University \College of Education

ABSTRACT

Email: muntaha51@yahoo.com

The problem of the research becomes clear to the necessity of the university administration to keep pace with developments and technologies, and its management must be transferred from the traditional university administration that depends on paper transactions to an electronic administration that relies on information technology as an essential element in the completion of its work. The importance of a topic comes to the importance of electronic management and the need to apply it in the administrations of higher education institutions

The aim of the research is to identify the degree of application of electronic management in the scientific faculties of Al-Mustansiriya University from the point of view of the assistants, and what is the degree of application of electronic management in the faculties of Al-Mustansiriya University from the point of view of the heads of scientific departments.

What is the degree of application of electronic management in the faculties of Al-Mustansiriya University from the point of view of the assistants of the humanitarian faculties of Al-Mustansiriya University, and what is the degree of application of electronic management in the faculties of Al-Mustansiriya University from the point of view of the heads of departments of the humanities faculties of Al-Mustansiriya University

As the research identified the two samples of assistants and heads of departments who work in the scientific and humanities faculties of AlMustansiriya University, which numbered (117) individuals for the academic year (2021-2020), where the researcher identified a set of terms for research, on the theoretical side that are related to the subject and addressed a group of related studies In the subject of the research, a set of procedures were followed in terms of describing the research community and its sample, where a sample of (58) individuals was obtained, which is the ratio of $(50 \%)$ to the research community. The open question where the validity and reliability of the tool were carried out, then the research came out with a number of results, then presented and interpreted them. Then a set of conclusions, recommendations and proposals for the research were developed Keywords: level, electronic management, faculties, Al-Mustansiriya University, associates, heads of scientific departments . 
يشهد العالم اليوم نقلة نوعية في أساليب العمل تقوده تقنية المعلومات التي تنتشر في العالم في

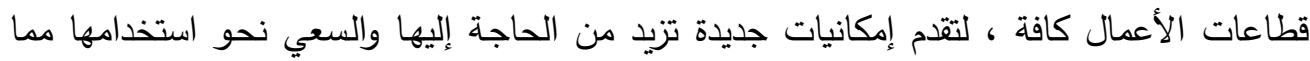

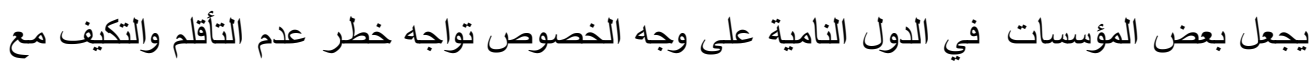

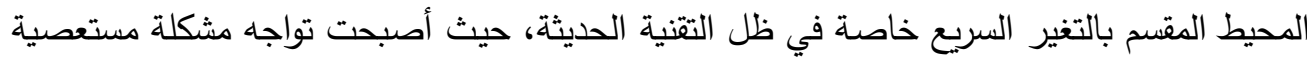
وهي عدم مقدرتها على التفاعل والتعامل مع معطيات العصر الحديث في مجال تقنية المعلومات

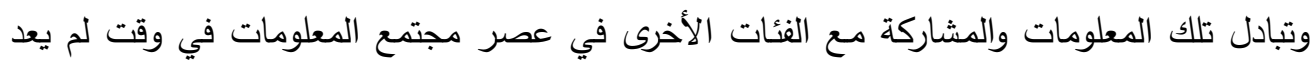

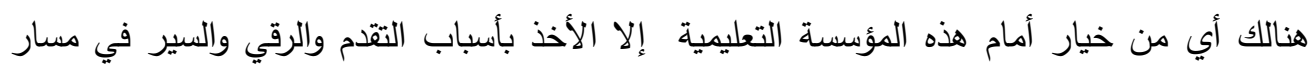

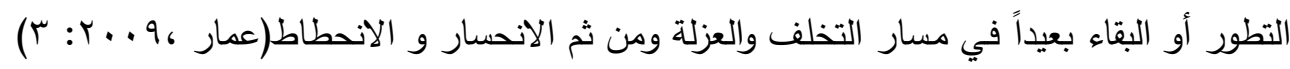

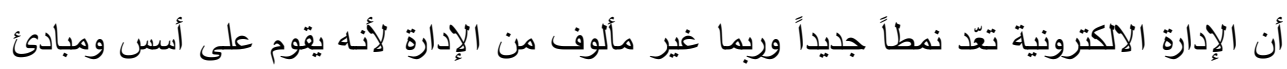

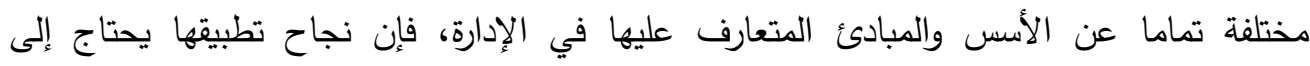

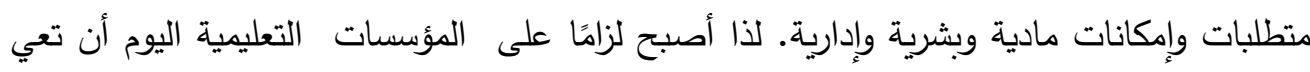

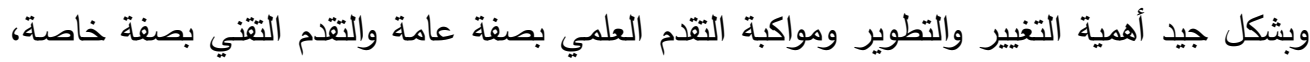
إذا أرادت مجرد الاستمرار والبقاء

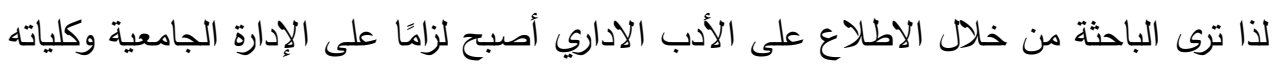

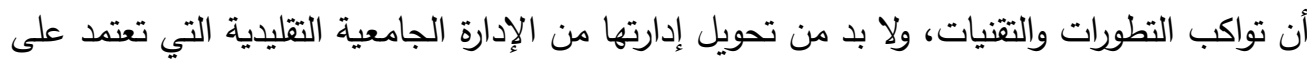

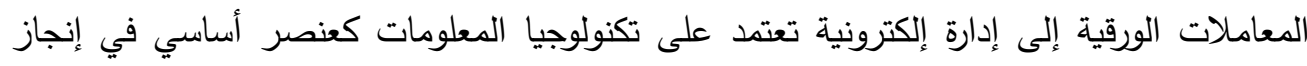

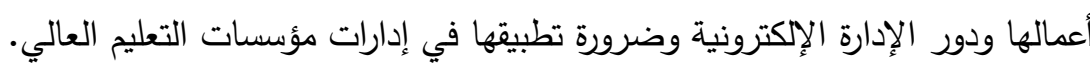

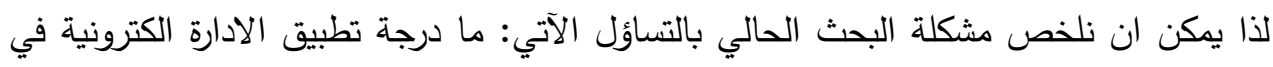
كليات الجامعة المستصرية من وجهة نظر المعاونين ورؤساء الأقسام العلمية.

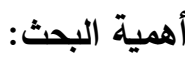
تستمد هذه الدراسة أهميتها من حداثة موضوع الإدارة الإلكترونية والندرة النسبية في البحوث

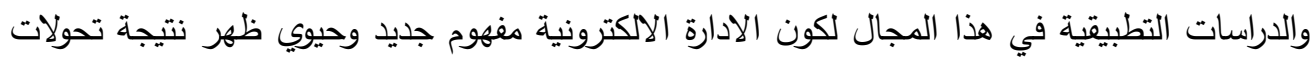

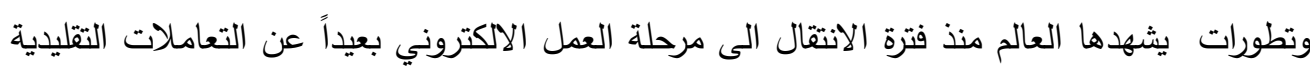

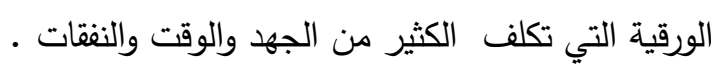
أسهم التقدم التكنولوجي الحديث في تطوير أساليب العمل الإداري في السنوات الأخيرة كما أتاح

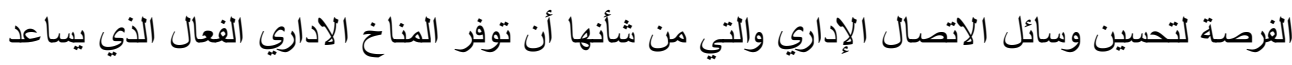




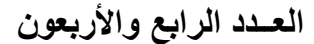

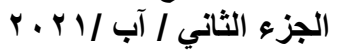

على اختصار الوقت والجهد، كل ذلك فرض على المؤسسات التحول من الأساليب التقليدية في إنجاز

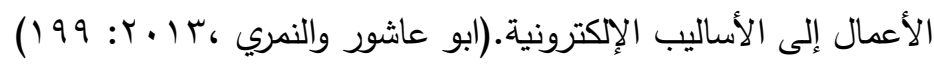

وتعّد الجامعة من المؤسسات التعليمية المهمة والتي تتحمل مسؤولية النهوض بالمجتمع وتتميته ، حيث توظف طاقاتها وامكاناتها لتحقيق اهدافها المتعلقة بالتعليم ، وإعداد الملاكات البشرية التي تمتلك المعرفة والعلم التي تمكنها من العمل في المجالات والتخصصات المختلفة كافة والنتاج العلمي فضلاً عن خدمة المجتمع ، وعليه لا يمكن للجامعة في أي مجتمع أن تؤدي دورها الحيوي وني في خدمة المجتمع وتتميته بجميع جوانبه السياسية والاقتصادية و المعرفية و الاجتماعية إلا من خلال الافادة من وسائل التقدم التكنولوجي في تطوير العمل الاداري ، بحيث يتم تحويل جميع العمليات الادارية ذات الطبيعة الورقية إلى عمليات ذات طبيعة الكترونية باستخدام مختلف التقنيات الالكترونية في الادارة ، وعليه شهدت السنوات الأخيرة اتجاهات جديدة في الادارة الجامعية تمثلت في تطبيق الإدارة من خلا استخدام الوسائل الإكترونية من قبل الادارات الجامعية في انجاز

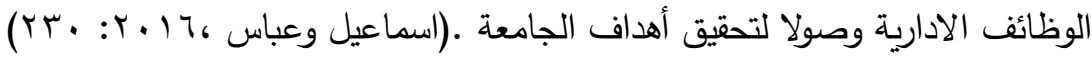

\section{اهداف البحث: يهدف البحث الحالي التعرف على:}

ا. ما درجة تطبيق الادارة الاككترونية في كليات الجامعة المستتصرية من وجهة نظر المعاونين العلمي. ז. ما درجة تطبيق الادارة الاككترونية في كليات الجامعة المستصرية من وجهة نظر رؤساء الأقسام العلمية . ז. ما درجة تطبيق الادارة الاككترونية في كليات الجامعة المستصرية من وجهة نظر معاوني الكليات الانسانية للجامعة المستتصرية . ع. ما درجة تطبيق الادارة الالكترونية في كليات الجامعة المستصرية من وجهة نظر رؤساء الأقسام للكليات الانسانية للجامعة المستنصرية . حدود البحث:

يتحدد البحث الحالي بمعاوني ورؤساء الأقسام العلمية للكليات العلمية والانسانية الجامعة المستتصرية

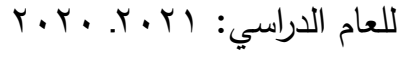




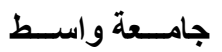

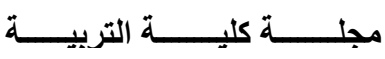

تحديد المصطلحات:

الادارة الالكترونية: عرفهاكل من:

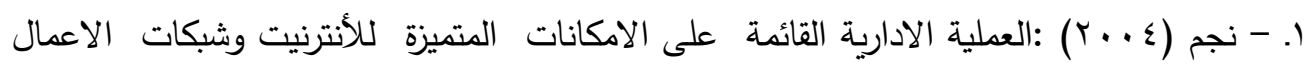
في التخطيط والتوجيه والرقابة على الموارد الكترونيا بدون حدود من أجل تحقيق أهداف المنظمة

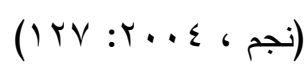

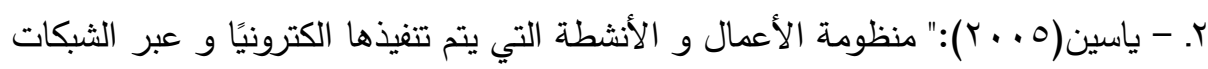
"و إذا اقتبسنا التعريف الكلاسيكي للإدارة باعتبارها وظيفة إنجاز الأعمال من خلال الآخرين فإن بإمكاننا القول أن الإدارة الالكترونية هي وظيفة إنجاز الأعمال باستخدام النظم و الوسائل

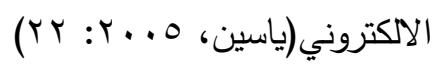

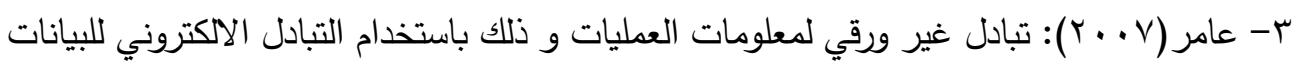
أو أو هي استخدام كل الوسائل الاككترونية في إنجاز كل أعمال و معاملات المنظمة مثل استخدام

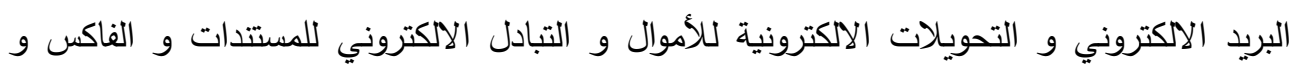

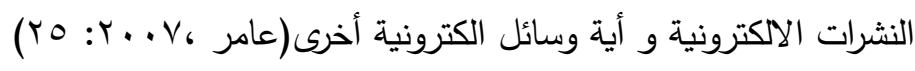

التعريف النظري: استخدام نظم المعلومات و شبكات الحاسوب و الاتصالات في تتفيذ المهام و الأعمال الإدارية مما يؤدي إلى إنجازها بسهولة و يسر و دقة عالية و تعمل على توفير الوقت و الجهد و تبسيط الإجراءات مع ضمان خصوصية و أمن المعلومات.

$$
\text { التعريف الاجرائي: }
$$

ويقاس بالدرجة التي يحصل عليها المستجيب من خلال الإجابة عن فقرات أداة الادارة الالكترونية .

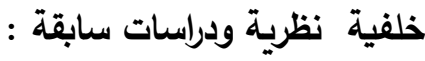

مفهوم الإدارة الإلكترونية:

يعّد مفهوم الإدارة الإلكترونية واحداً من المفاهيم الحديثة في الفكر الإداري المعاصر ، فهي تعد

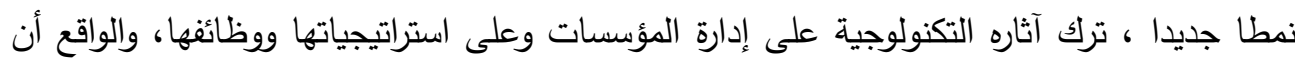
هذه التأثيرات لا تعود فقط إلى البعد التكنولوجي المتمثل بالتكنولوجيات الرقمية، وإنما يمتد أيضا إلى البعد الإداري المتمثل في تطوير المفاهيم الإدارية التي تراكمت لعقود عديدة، وأصبحت تعمل على تحقيق المزيد من المرونة الإدارية في التمكين الإداري(عبابنه والجبالي ، 9 ـ ـب: هبr) 


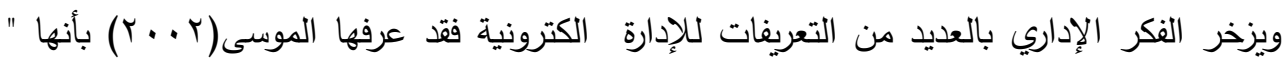

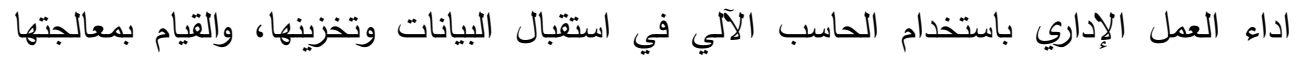

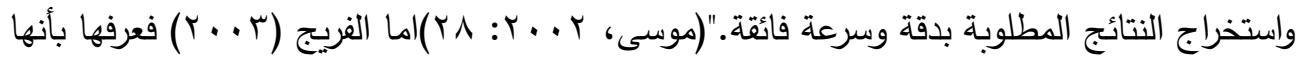

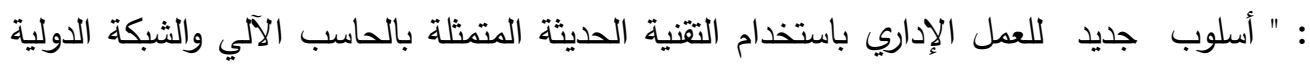

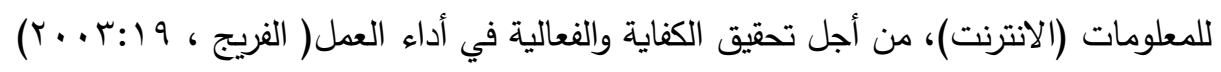
أهداف الادارة الاككترونية : الاترن

الإدارة الإلكترونية طريقة فاعلة من طرق الإدارة الحديثة التي تعمل على رفع سوية العمل الإداري

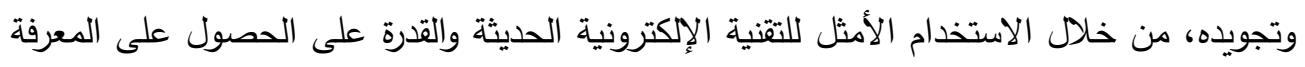

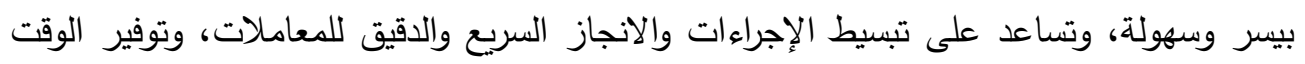

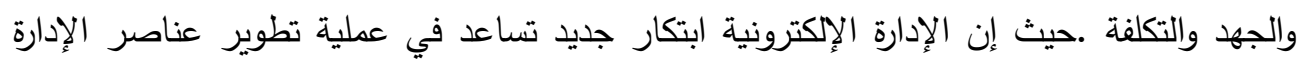

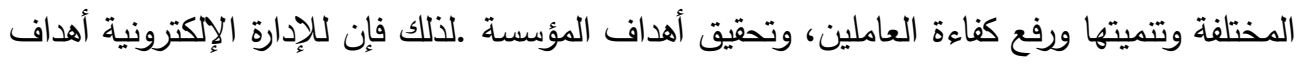
كثيرة تسعى إلى تحقيقها في إطار تعاملها مع المستفيد، ويمكن تقسيمها كما يأتي:

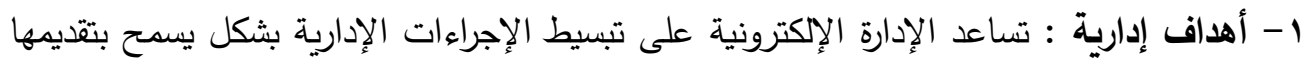

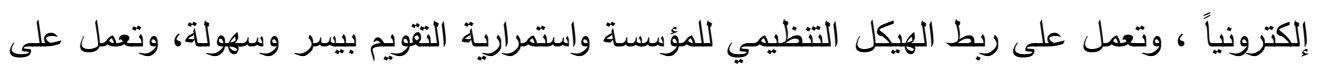
انسياب الاتصال بين أجزاء المؤسسة المختلفة؛ مما يساعد في الحصول على المعلومات والخدمات

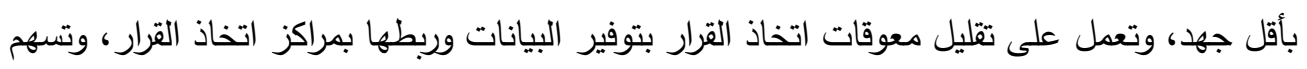
في إنجاز عمليات الحفظ والتحليل التي تيسر عملية صناعة القرارات بثكل سريع ودقيق وفاعل

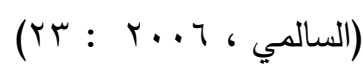
r- أهداف اجتماعية : تعمل الإدارة الإكترونية على تعزيز الحصول على الخدمات للمستخدمين

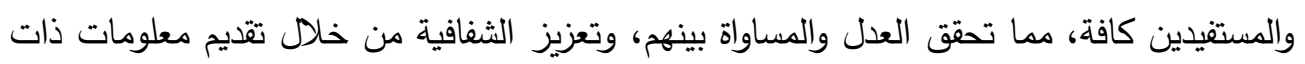

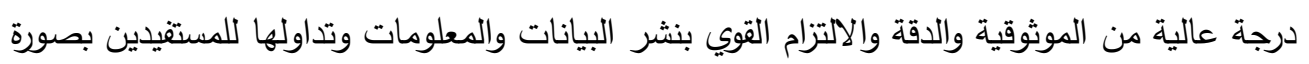
فورية. r- أهداف اقتصادي: تسعى الإدارة الإككترونية إلى تحسين مستوى الخدمات وتوفير الوقت والمال-

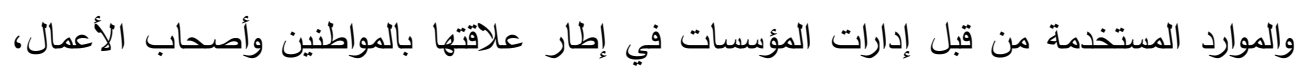

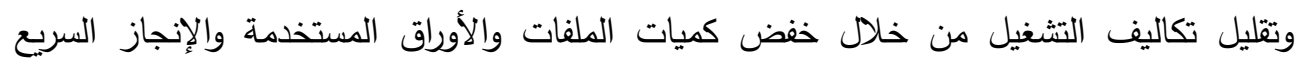

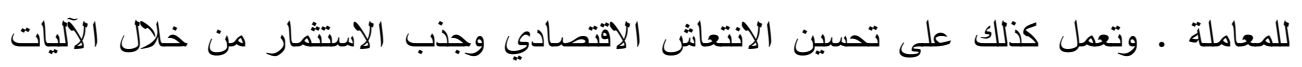

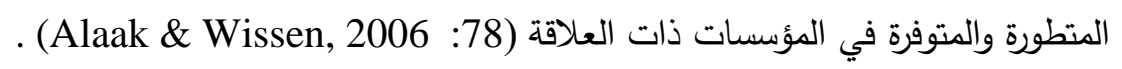




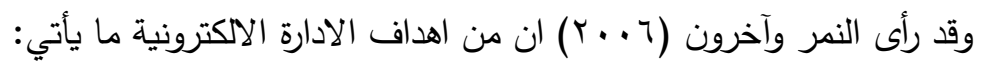
1- أهداف مباشرة يمكن ترجمتها الى مكاسب مادية مثل: الانجاز السريع للأعمال ، وتقليل

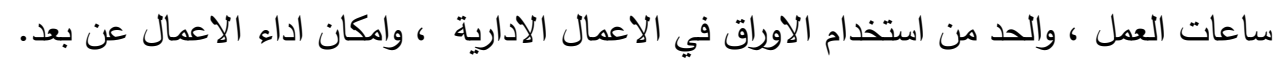

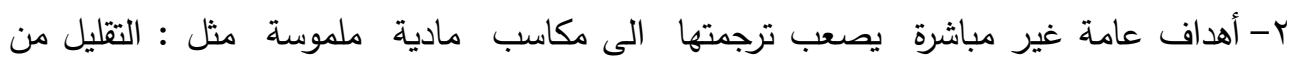

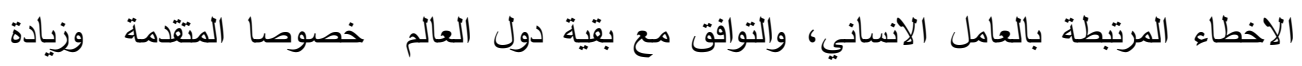

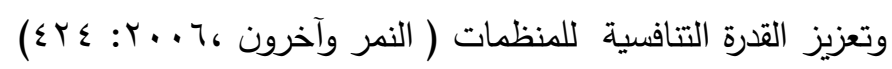

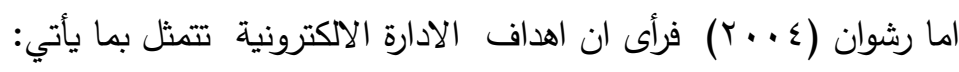

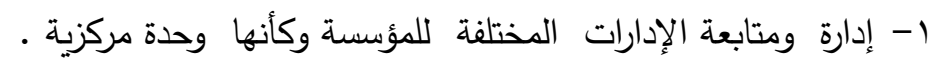

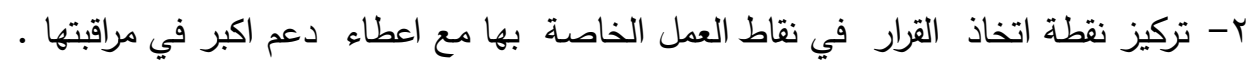

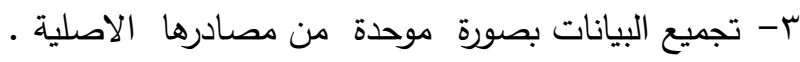

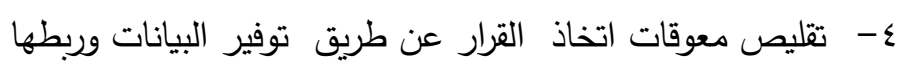
ه- توظيف تكنولوجيا المعلومات من أجل دعم وبناء ثثقافة مؤسسية إيجابية لاى كافة العاملين.

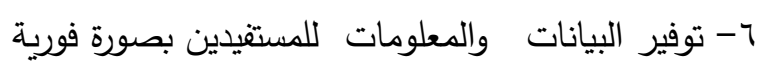

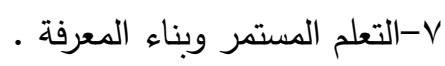

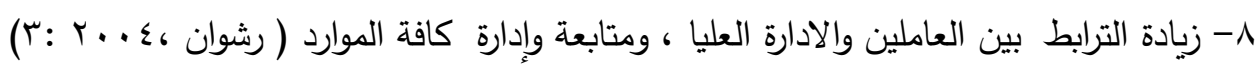

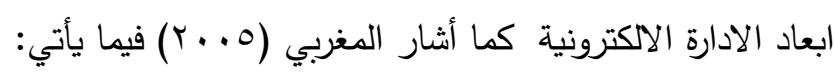

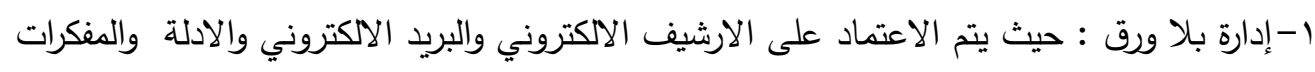

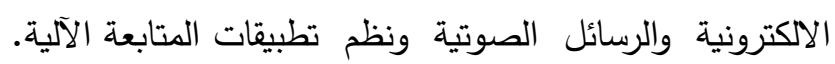

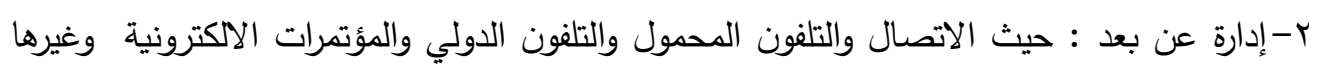

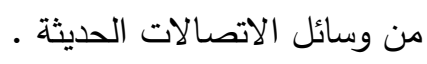

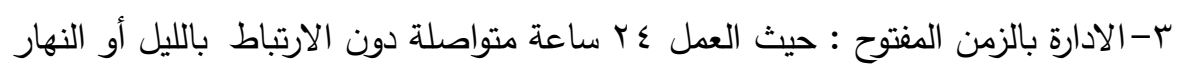

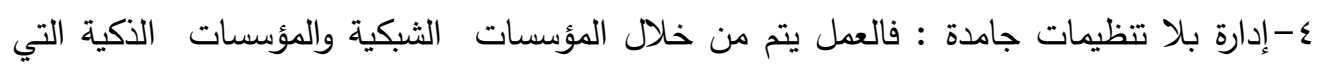

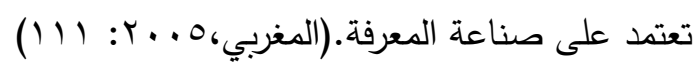


يمكن تلخيص وظائف الادارة الالكترونية بما يأتي:

1- التخطيط : يختلف التخطيط الإكتروني عن التخطيط التقليدي بتوفر المرونة والسهولة والدقة

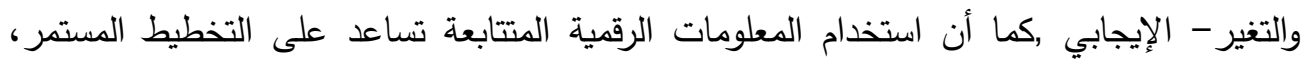

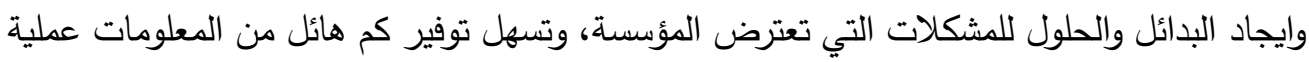

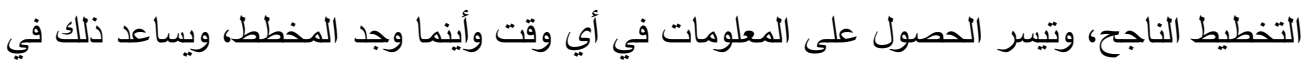

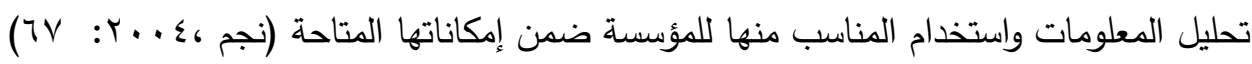

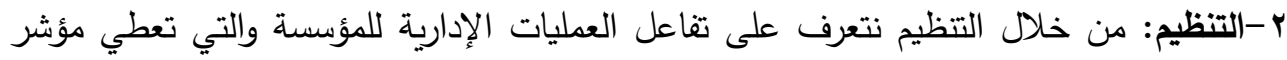
التحقيق- أهداف المؤسسة وتهيء الظروف في الحصول على منتجات منافسة ومتميزة من خلال

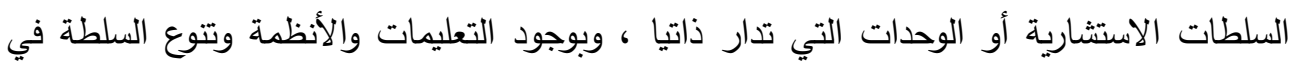

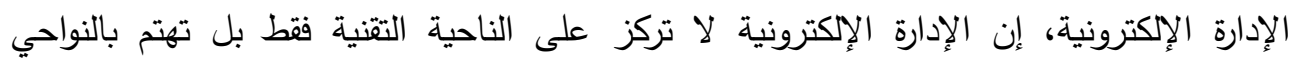
الإنسانية، وبعملية تطوير وتحسين الإجراءات والوصف الوظيفي للعاملين، واستثمار طاقاتهم لتقديم

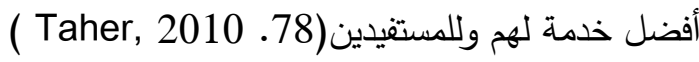

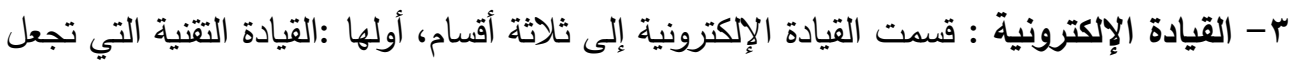

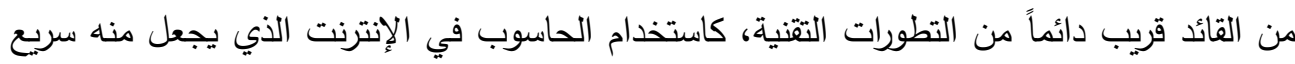

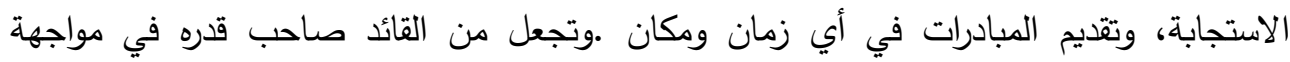

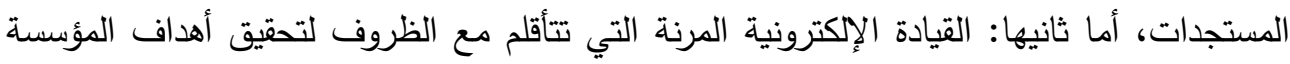

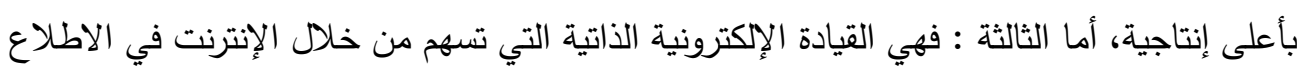

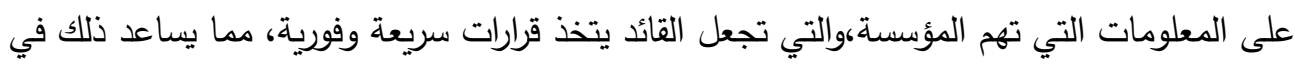
تنفيذ الأعمال بيسر وسهولة.(Berri, 2005:21)

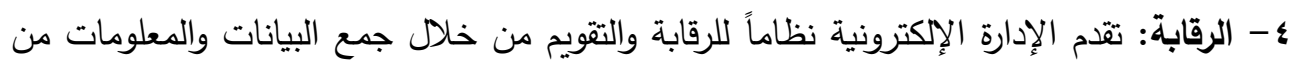

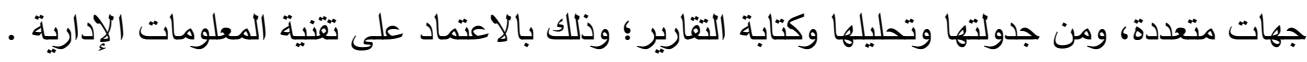
وكذلك تتم الرقابة عن بعد واكتثاف الأخطاء وقت التنفيذ، وهذا ما يوفر المعالجة الفورية للأخطاء .

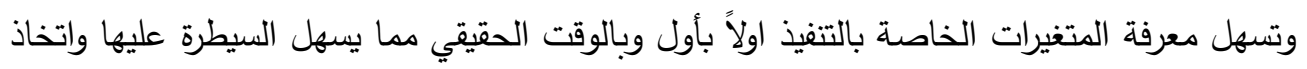

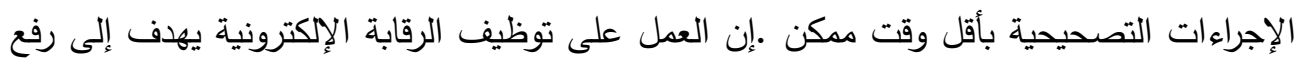

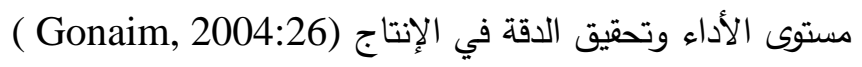


المبررات التي تدعو إلى التحول نحو الإدارة الإلكترونية في مؤسسات التعليم ان هناك الكثير من المبررات التي دعت الى التحول نحو الادارة الالكترونية وهي: كم ذكرها

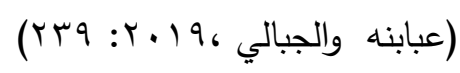
1- التسارع في الثورة التكنولوجية والمعرفية

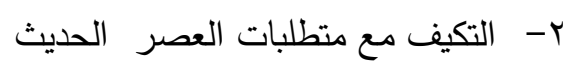
r- السعي إلى تحقيق الكفاية الإدارية النوعية والكمية الملائمة للفكر الإداري التقني المعاصر

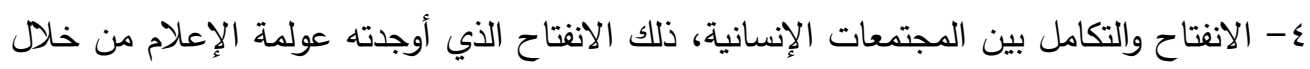

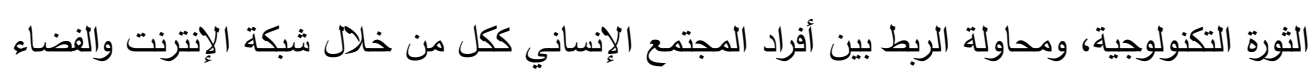
الإلكتروني.

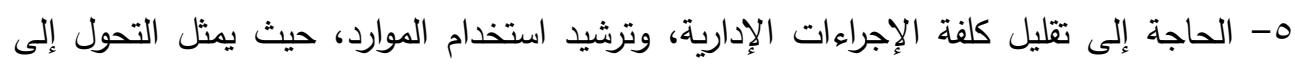

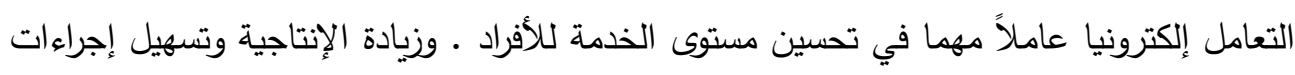

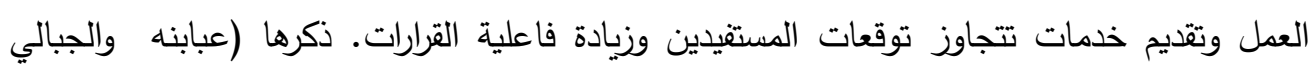
(rrq: $r \cdot 19$ ،

دراسات سابقة :

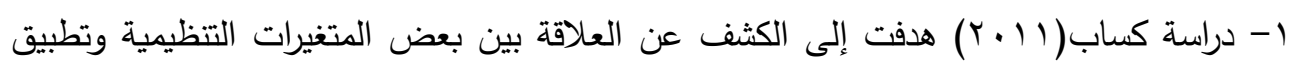

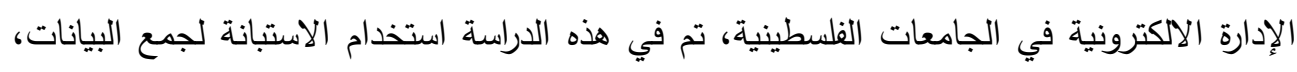

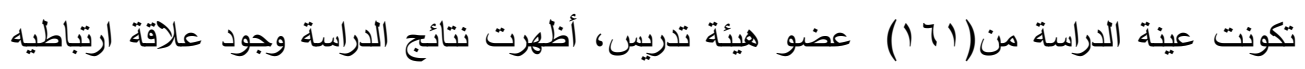

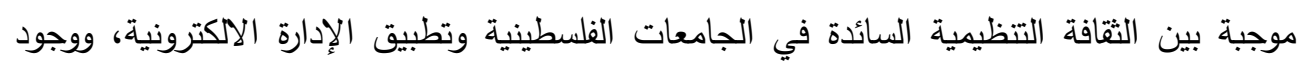

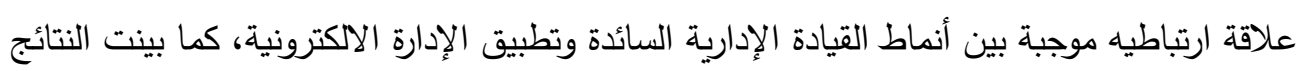

وجود اختلاف في اهتما الجامعات بتوفير متطلبات تطبيق الإدارة الاككترونية، حيث كان هناك قصور في إصدار التشريعات، وتطوير التظظيم الإداري وتدريب العاملين على تطبيقات الإدارة الآكترونية.

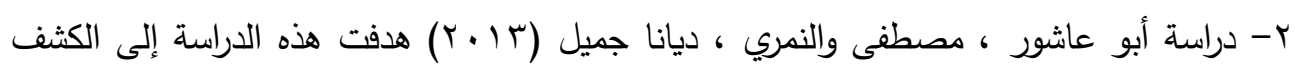

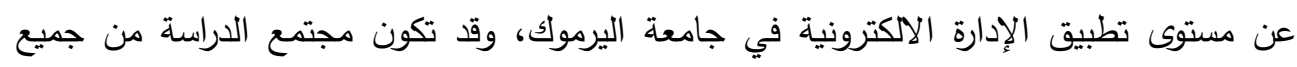

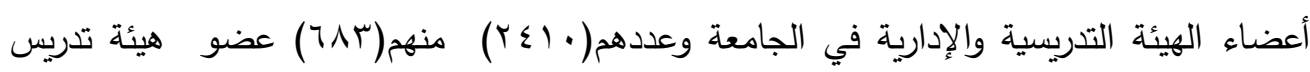




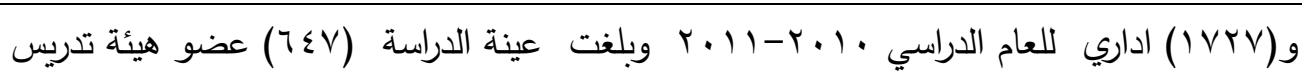

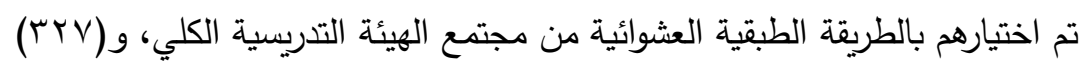

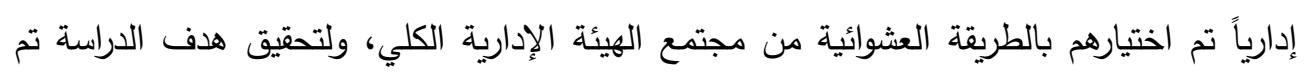

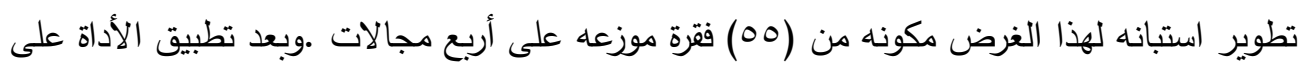

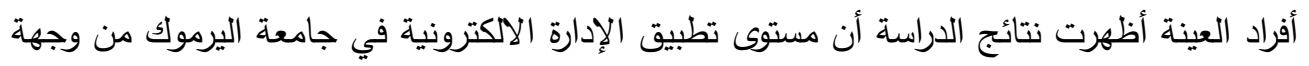

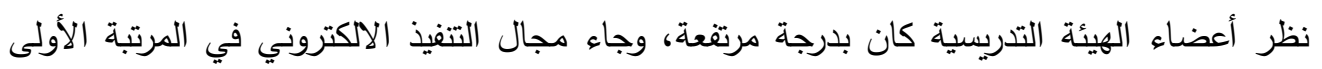

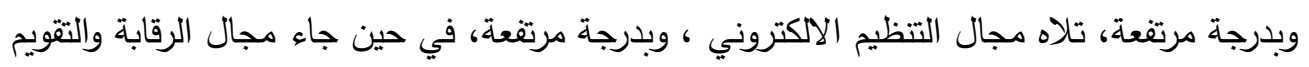

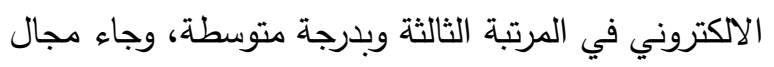

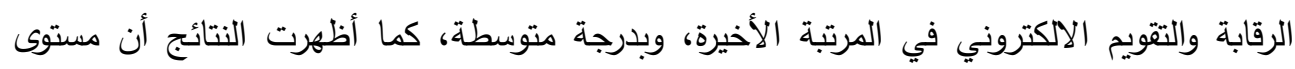

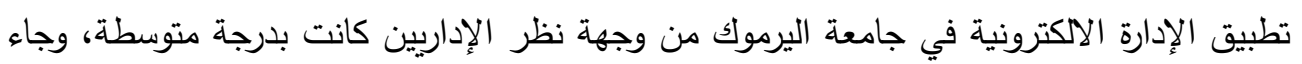

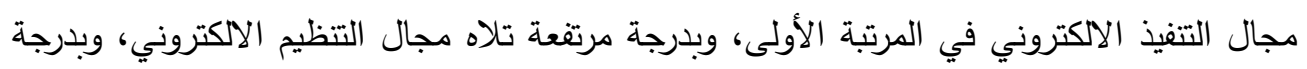

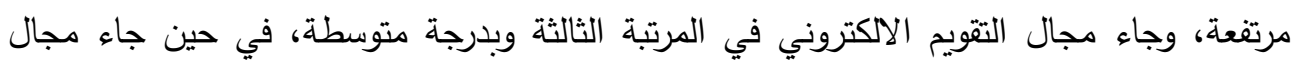

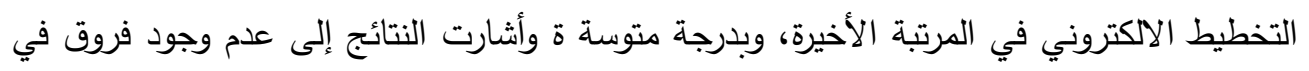

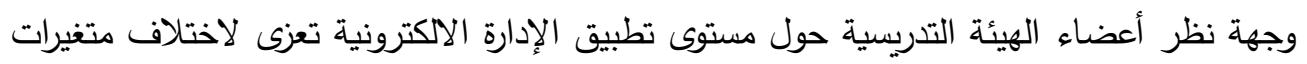

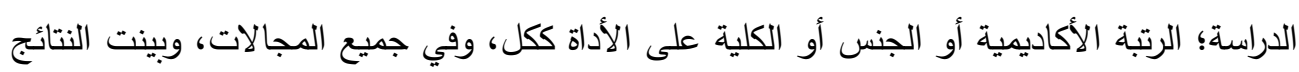

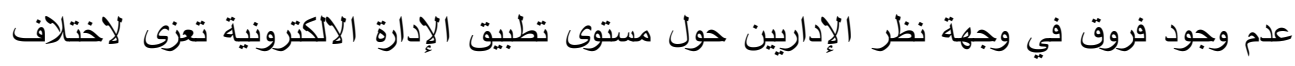

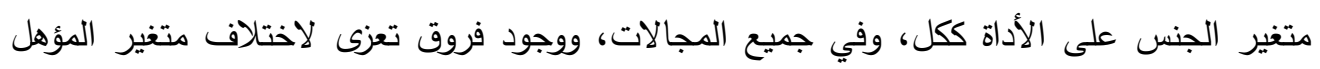

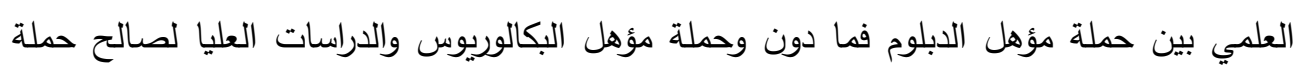
البكالوريوس والدراسات العليا في مجالي التخطيط الالكتروني.

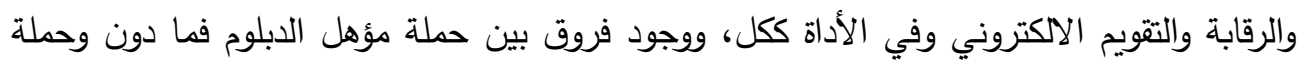

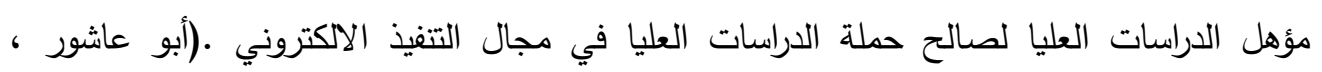

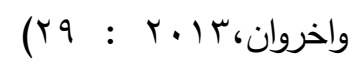

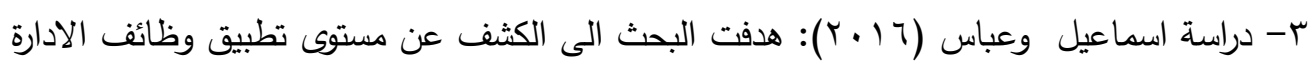
الاككترونية (التخطيط الالكتروني ، التتظيم الالكتروني ، القيادة الالكترونية ، الرقابة الالكترونية)

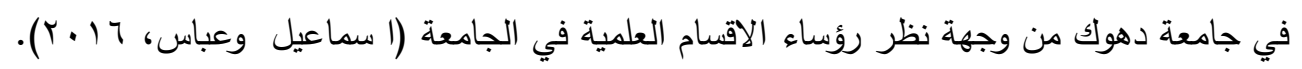




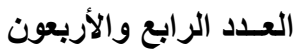

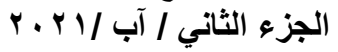

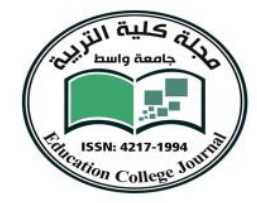

- استخدمت الاستبانة لجمع بيانات الجانب الميداني حيث وزعت على رؤساء الاقسام العلمية في كليات الجامعة وعددهم (^§) رئيس قسم وكانت النتائج ان مستوى تطبيق الادارة الالكترونية كانت مرتفعة واشارت ايضا الى وجود فروقات معنوية في وجهات نظر رؤساء الأقسام العلمية حول مستوى تطبيق الادارة الالكترونية تعزى لخصائصهم الفردية ، وعدم وجود فروقات معنوية في وجهات نظرهم تبعا لمدة الخدمة ، والتخصص .

ع- دراسة عبابنة والجبالي(9 (ب) ) : هدفت الدراسة الحالية الكثف عن مستوى تطبيق الإدارة الإككترونية في كلية السنة التحضيرية بجامعة حائل وتكونت عينة الدراسة من جميع رؤساء الأقسام

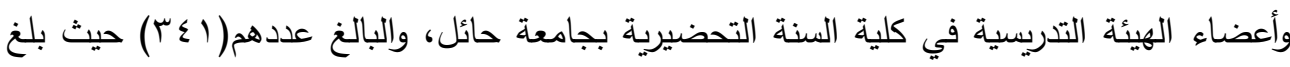

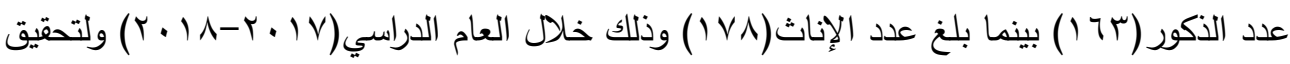

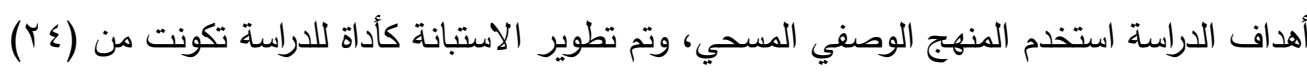
فقرة وتوصلت نتائج الدراسة إلى أن مستوى تطبيق فقرات الاستبانة ككل على عينة الدراسة جاءت بمستوى متوسط، وأن هنالك تباينا ظاهريا لمستوى تطبيق الإدارة الإكترونية لدى رؤساء الأقسام وأعضاء هيئة التدريس بحسب متغيرات الدراسة، وإلى عدم وجود فروق ذات دلالة إحصائية لمستوى تطبيق الإدارة الإلكترونية لاى رؤساء الأقسام وأعضاء هيئة التدريس تعزى لأثر الوظيفة، ووجود فروق دالة إحصائيا تعزى لأثر الجنس وجاءت الفروق لصالح الذكور، ووجود فروق دالة إحصائيا تعزى لأثر الرتبة الأكاديمية وجاءت الفروق لصالح رتبة أستاذ مشارك فما فوق .وفي ضوء النتائج المذكورة تم اقتراح عدد من التوصيات منها ضرورة توعية جميع العاملين وأعضاء هيئة التدريس بدور الإدارة الإكترونية وأهميتها، وتطوير البرامج التدربية وفق احتياجاتهم للعمل في ظل الإدارة

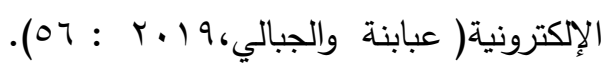
منهجية البحث اجراء اته:

منهج البحث: استخدمت الباحثة منهج البحث المسحي الوصفي التحليلي في هذه الدراسة،بوصفه المنهج الأكثر ملائمة للدراسة الحالية ويهتم هذا المنهج بوصف الجوانب المتنوعة لمشكلة البحث إذ جرى توظيف استبانة محكمة، بهدف التوصل إلى نتائج البحث الحالي. مجتمع البحث: تكون مجتمع البحث من رؤساء الاقسام ومعاوني كليات الجامعة المستتصرية المتكون

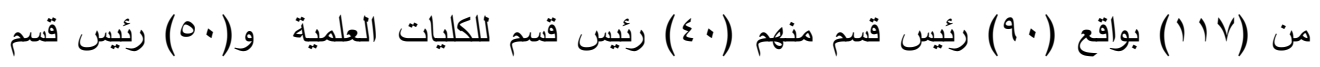
للكليات الانسانية واقع (YV) معاون قسم منهم (· ( ) معاون للكليات العلمية و(IV) معاون

للكليات الانسانية كما في الجدول (1) 


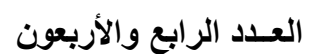

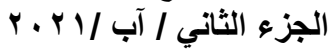

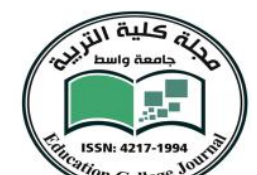

$\underbrace{30 \%}_{\text {irion Collepe }}$

\section{جامسـعة واســط

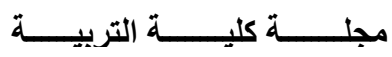

\begin{tabular}{|c|c|c|c|c|c|c|}
\hline المجموع الكلي & \multicolumn{2}{|c|}{ الانسانية } & \multicolumn{2}{|c|}{ العلمية } & الكلية & $ت$ \\
\hline رئيس القسم & المعاون & القبسم & المعاون & رائيس & & \\
\hline 14 & - & - & r & 11 & كلية الطب & -1 \\
\hline 9 & - & - & $r$ & $\mathrm{v}$ & كلية العلوم & $-r$ \\
\hline 9 & - & - & $r$ & $\mathrm{v}$ & كلية الهندسة & $-r$ \\
\hline 1. & - & - & r & $\Lambda$ & كلية طب الاسنان & $-\xi$ \\
\hline 9 & - & - & Y & $\mathrm{V}$ & كلية الصيدلة & -0 \\
\hline 0 & $r$ & $r$ & - & - & كلية القانون & -7 \\
\hline IY & r & 1. & - & - & كلية الاداب & $-V$ \\
\hline 11 & $r$ & $\Lambda$ & - & - & كلية التربية & $-\wedge$ \\
\hline$\Lambda$ & $r$ & 7 & - & - & وللية الادارة & -9 \\
\hline 0 & $r$ & $r$ & - & - & كلية العلوم السياسة & -1 \\
\hline 17 & $r$ & $1 \leqslant$ & - & - & كلية التربية الاساسية & -11 \\
\hline 7 & $r$ & $\varepsilon$ & - & - & وكلية البدنية الرياضية & -14 \\
\hline$\varepsilon$ & $r$ & $r$ & - & - & كلية العلوم السياحية & -14 \\
\hline $11 \mathrm{~V}$ & IV & 0. & 1. & $\varepsilon$. & المجموع الكلى & \\
\hline
\end{tabular}

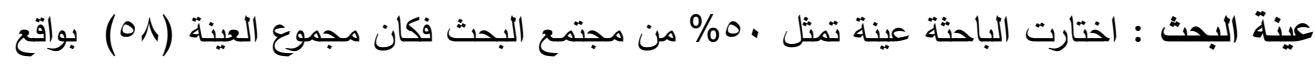

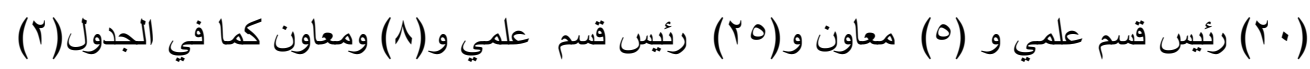

\begin{tabular}{|c|c|c|c|c|c|c|}
\hline \multicolumn{7}{|c|}{ عينة البحث } \\
\hline المجموع الكلي & & الانسانية & & العلمية & الكلية & ت \\
\hline رئيس القسم والمعاون & المعاون & رئيس القسم & المعاون & رئيس القسم & & \\
\hline $\mathrm{V}$ & - & - & 1 & 7 & كلية الطب & -1 \\
\hline$\varepsilon$ & - & - & 1 & $r$ & كلية العلوم & -4 \\
\hline 0 & - & - & 1 & $\varepsilon$ & كلية الهندسة & -4 \\
\hline 0 & - & - & 1 & $\varepsilon$ & كلية طب الاسنان & $-\varepsilon$ \\
\hline$\varepsilon$ & - & - & 1 & $r$ & كلية الصيدلة & -0 \\
\hline$r$ & 1 & $r$ & - & - & كلية القانون & -7 \\
\hline 7 & 1 & 0 & - & - & كلية الاداب & $-V$ \\
\hline 7 & 1 & $\varepsilon$ & - & - & كلية التربية & -1 \\
\hline$\varepsilon$ & 1 & $r$ & - & - & كلية الادارة و الاقتصاد & -9 \\
\hline$r$ & 1 & 1 & - & - & كلية العلوم السياسة & -1. \\
\hline$\Lambda$ & 1 & $\mathrm{~V}$ & - & - & كلية التربية الاساسية & -11 \\
\hline$r$ & 1 & $r$ & - & - & ولية البلوم الرياضية $\quad$ الرياضية & $-1 Y$ \\
\hline$r$ & 1 & 1 & - & - & كلية العلوم السياحية & -14 \\
\hline 01 & $\Lambda$ & ro & 0 & $r$. & المجمو ع الكلى & \\
\hline
\end{tabular}


اداة البحث: تم اعداد استبانة لقياس درجة ممارسة رؤساء الاقسام ومعاوني الكليات الجامعة

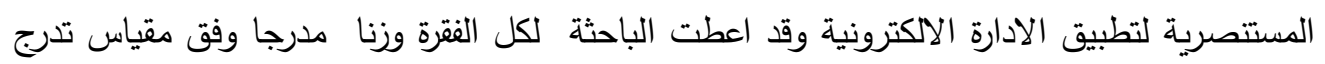

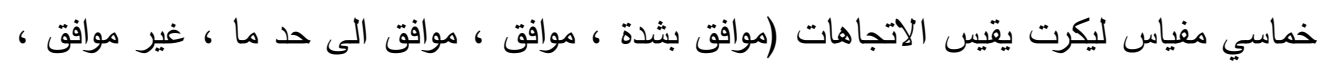

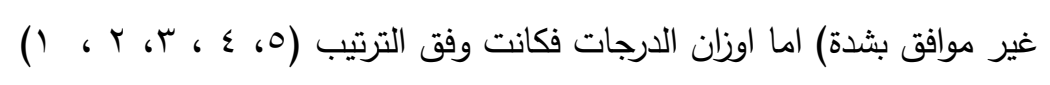

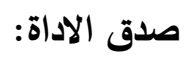

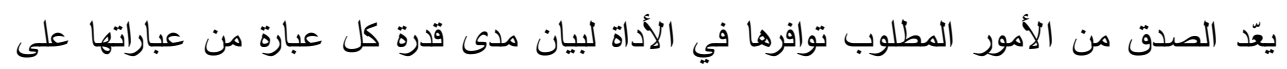

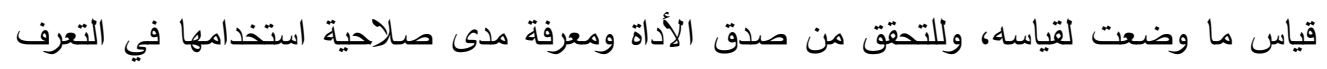

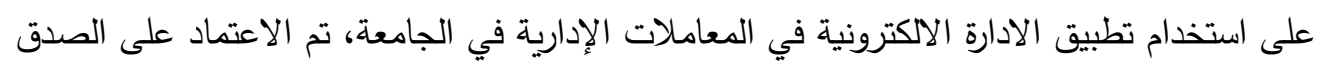

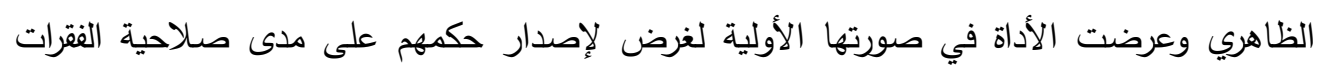
وسلامة صياغتها وملاءمتها لموضوع البحث الحالي على مجموعة من المحكمين في مجال الإدارة

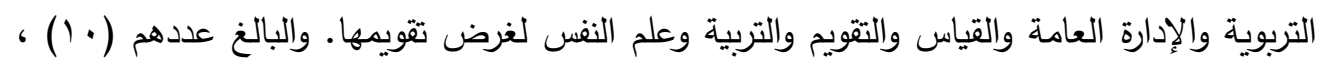

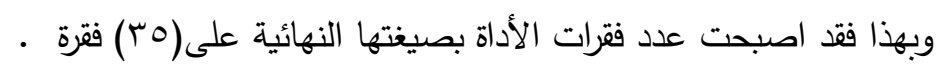

ثبات الاداة

للتأكد من ثبات أداة الدراسة استخدم الباحث طريقة الفا كرونباخ لحساب معامل الثبات إذ بلغ معامل

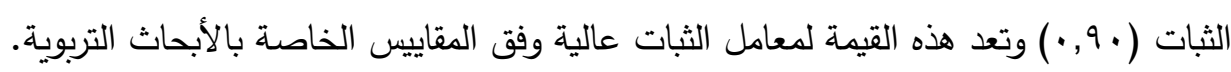

\section{تفسير نتائج البحث:}

بعد التحليل الاحصائي للاستبانات المقدمة لعينة البحث وعلى وفق اهداف البحث وهي:

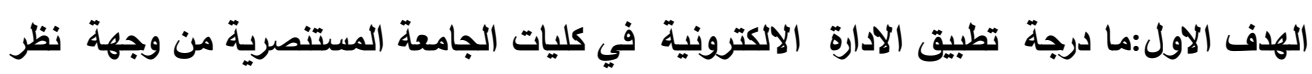

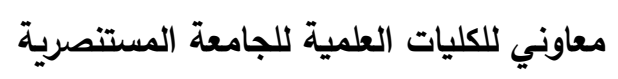
للاجابة عن الهدف الاول تم استخراج المتوسطات المرجحة والوزن المئوي لفقرات الاستبانة كما هو الهوبه مبين في الجدول (r) المتوسطات المرجحة والاوزان المئوية لفقرات درجة تطبيق الادارة الالكترونية من وجهة نظر معاوني كليات العلمية لجامعة المستترية مرتبة ترتيبيا تنازليا 
العـدد الرابع والأربعون

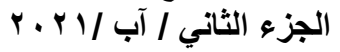

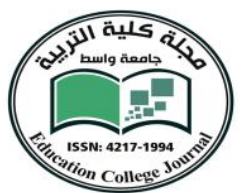

ision College 30

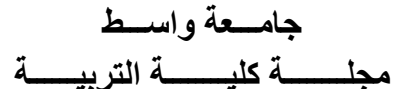

\begin{tabular}{|c|c|c|c|c|c|c|c|c|c|}
\hline 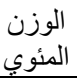 & المرجح & لا لاو افق & لا او افق & محايد & او افق & او افق بشدة & الفقرة & المرتبة & الاستباند \\
\hline$\%$ & 0 & - & - & - & - & 0 & 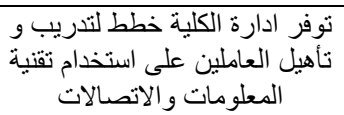 & 1 & $\pi$ \\
\hline$\ddot{\%}$ & 0 & - & - & - & - & 0 & استخدام الحاسوب و والانترنتي & $T$ & 11 \\
\hline$\ddot{\%}$ & 0 & - & - & - & - & 0 & يوجد إدارة أو قارم للحاسوب في . & $T$ & $r$. \\
\hline$\ddot{\%}$ & 0 & - & - & - & - & 0 & سياسة تطبيق الإدارة الالكترونية الكية الكلية & 1 & r) \\
\hline$\ddot{\%}$ & $\varepsilon .0$ & - & - & - & - & 0 & 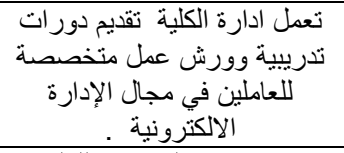 & $T$ & YT \\
\hline$\% 9 r$ & $\varepsilon .7$ & - & - & - & $r$ & $r$ & 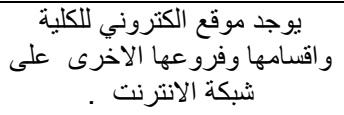 & $\bar{r}$ & 11 \\
\hline$\% \wedge \wedge$ & $\varepsilon . \varepsilon$ & - & - & - & $r$ & $r$ & توجد في الكلية أقسام متخصصية الإدرارة الإلكترونية & $r$ & YY \\
\hline$\%^{\wedge \wedge}$ & $\varepsilon . \varepsilon$ & - & - & - & $r$ & $r$ & 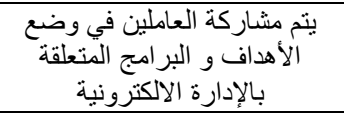 & $\Gamma$ & rq \\
\hline$\% \wedge \wedge$ & $\varepsilon . \varepsilon$ & - & - & - & $\bar{r}$ & $r$ & 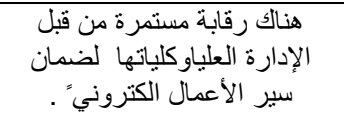 & $r$ & $r$. \\
\hline$\% \wedge$. & $\xi$ & - & - & - & 0 & - & 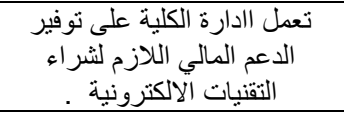 & $\varepsilon$ & $T$ \\
\hline$\%^{\wedge}$. & $\varepsilon$ & - & - & - & 0 & - & يو شد ربطة بين شنبكة الكلية و & $\varepsilon$ & 1. \\
\hline$\% \wedge$. & $\varepsilon$ & - & - & - & 0 & - & 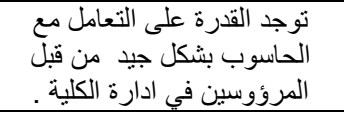 & $\varepsilon$ & $1 \varepsilon$ \\
\hline$\% \wedge$. & $\varepsilon$ & - & - & - & 0 & - & تقينية المعلومات والكلية متخصصون تصالات. & $\varepsilon$ & 10 \\
\hline$\% \wedge$. & $\varepsilon$ & - & - & - & 0 & - & 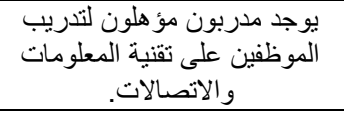 & $\varepsilon$ & 17 \\
\hline$\% \wedge$. & $\varepsilon$ & - & - & - & 0 & - & 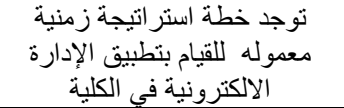 & $\varepsilon$ & YT \\
\hline$\% \wedge$. & $\varepsilon$ & - & - & - & 0 & - & 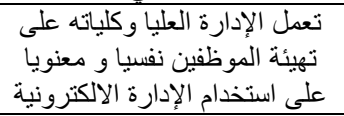 & $\varepsilon$ & $T \varepsilon$ \\
\hline$\%^{\wedge}$. & $\varepsilon$ & - & - & - & 0 & - & 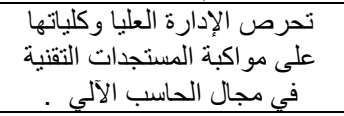 & $\varepsilon$ & $r \wedge$ \\
\hline
\end{tabular}




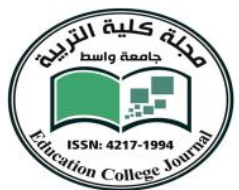

iton College
العـدد الرابع والأربعون

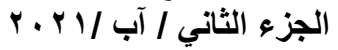

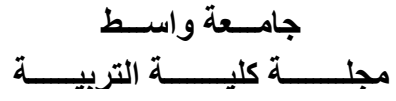

\begin{tabular}{|c|c|c|c|c|c|c|c|c|c|}
\hline$\% \wedge$. & $\overline{\varepsilon \varepsilon}$ & - & - & - & 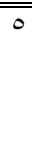 & - & 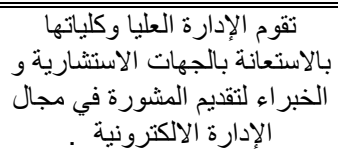 & $\varepsilon$ & TI \\
\hline$\% \wedge$ & $\varepsilon$ & - & - & - & 0 & - & 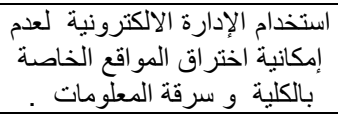 & $\varepsilon$ & Tr \\
\hline$\% \wedge$ & $\varepsilon$ & - & - & - & 0 & - & 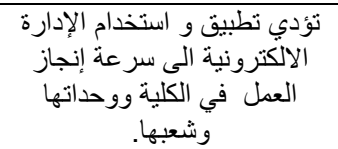 & $\varepsilon$ & Tr \\
\hline$\% \wedge$. & $\varepsilon$ & - & - & - & 0 & - & المعلو الاحتفاظ بنسخ إضات الكترونية الخاصنة من & $\varepsilon$ & $r \leqslant$ \\
\hline$\% \vee r$ & $r .7$ & - & - & $r$ & $r$ & - & 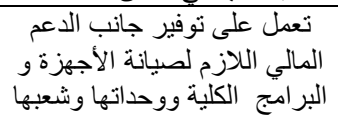 & 0 & $r$ \\
\hline$\% \vee r$ & r. & - & - & $r$ & $r$ & - & 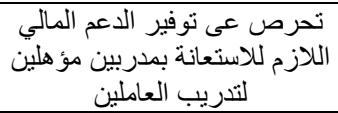 & 0 & $\varepsilon$ \\
\hline$\% \vee r$ & r. & - & - & $r$ & $r$ & - & الإدارة الالكترونبية الآلي اللازمة الحديثة بشبيق أجهزة & 0 & 7 \\
\hline$\% \vee r$ & $r .7$ & - & - & $r$ & $r$ & - & 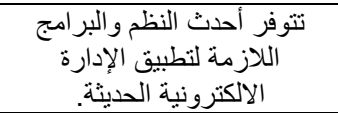 & 0 & V \\
\hline$\% \vee r$ & $r .7$ & - & - & $r$ & $r$ & - & يوجد خبر اء لتصميم و تطوير البكرونية & 0 & IV \\
\hline$\% \vee r$ & r. & - & - & $r$ & $r$ & - & البشرية في اللازمة لتطبيث الإدلية الموارد & 0 & 19 \\
\hline$\% \curlyvee \wedge$ & $r . \varepsilon$ & - & - & $r$ & $r$ & - & 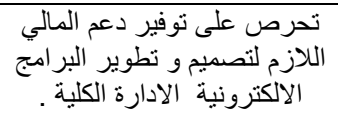 & 7 & $r$ \\
\hline$\% \curlyvee \wedge$ & $r . \varepsilon$ & - & - & $r$ & $r$ & - & 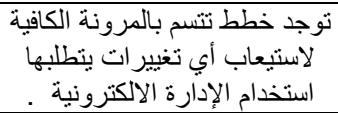 & 7 & YV \\
\hline$\% 7$. & $r$ & - & - & 0 & - & - & حاسوب تصنل إلى جميع الإة الكلية شبكة & $\mathrm{V}$ & $\wedge$ \\
\hline$\% 7$. & $r$ & - & - & 0 & - & - & 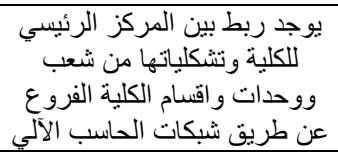 & $\mathrm{V}$ & 9 \\
\hline$\% 07$ & Y.A & - & - & $r$ & $r$ & - & لأستعادة البيانات في ادارة الكلية آلية اللية تلفها & $\Lambda$ & ro \\
\hline
\end{tabular}


العــد الرابع والاربعون

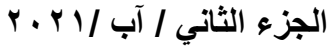

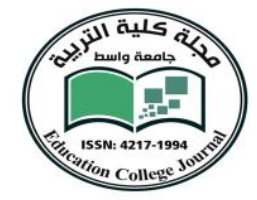

\begin{tabular}{|c|c|c|c|c|c|c|c|c|c|}
\hline$\% \circ r$ & $\overline{T .7}$ & - & $\bar{r}$ & $\bar{r}$ & - & - & حو افزل للمتميزين في الكلى توفير نظال اداء & 79 & 0 \\
\hline$\%$ or & T.T & - & 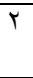 & $r$ & - & - & يتم استخدام البريد الكتروني في . العلية & 9 & $T$ \\
\hline$\% \leqslant 1$ & $r, \xi$ & - & $r$ & $r$ & - & - & تو واضحة لدى الإدارة العليا سياسة لحماية & 1. & YO \\
\hline
\end{tabular}

يتبين من الجدول (r) ان المتوسطات المرجحة لتقديرات معاوني كليات الجامعة المستتصرية لفقرات

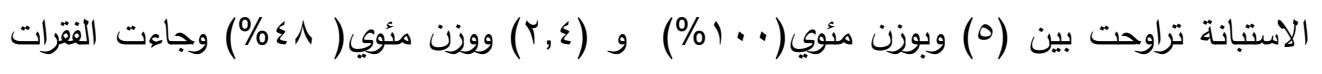

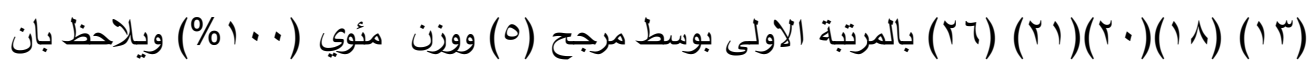
هذه الفقرات تتؤكد على البنية التحتية للادارة الكترونية من وجود خطط وتدريب وانترنيت اما الفقرات

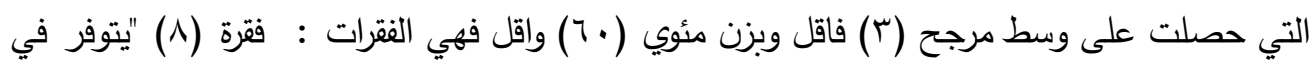
أدارة الكلية شبكة حاسوب تصل إلى جميع الاقسام ووحدات وشعب الكلية . " وهذا ضعف كبير لان من اهم اساسيات الادارة الاككترونية ووجود حاسبة الام التي تسيطر على كل حاسبات الكلية والفقرة (9)" يوجد ربط بين المركز الرئيسي للكلية وتثكلياتها من شعب ووحدات واقسام الكلية الفروع عن طريق شبكات الحاسب الآلي" وهذه الفقرة توضح بان لايمكن تطبيق الادارة الاككترونية اذا لم تربط

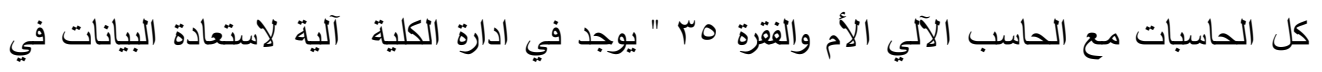
حالة تلفها أو تعطل الحاسبات الآلية ." وهذا النظام المفروض وجوده في الحاسبة الام والفقرة (0) "تعمل الكلية على توفير نظام حوافز للمتميزين في مجال اداء العمل الالكتروني " وهذا غير موجود فعلا فكيف نستطيع تطوير الادارة الالكترونية بدون حوافز •والفقرة (r l)" يتم استخدام البريد الكتروني في العمل داخل الكلية ." اذا البريد الكتروني استخدامه ضعيف داخل الكلية فكيف يمكن لن تطبيق الادارة الكترونية من خارج الكلية

الهدف الثاني: ما درجة تطبيق الادارة الاكترونية في كليات الجامعة المستصرية من وجهة نظر

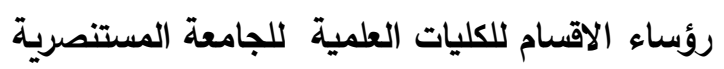
للاجابة عن الهدف الثاني تم استخراج المتوسطات المرجحة والوزن المئوي لفقرات الاستبانة من وجهة نظر رؤساء الاقسام للكليات العلمية للجامعة المستصرية كما هو مبين في الجدول(ع) المتوسطات المرجحة والوزن المئوي لفقرات الاستبانة من وجهة نظر رؤساء الاقسام للكليات العلمية للجامعة المستصرية 
العـدـد الرابع والأربعون

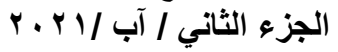

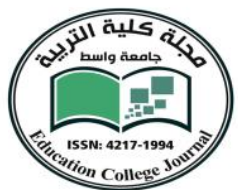

irion College

\begin{tabular}{|c|c|c|c|c|c|c|c|c|c|}
\hline 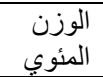 & المرجح & بلاوة افق & الا & محايد & او افق & بشدة & الفقرة & المرتبة & تالاستيانه \\
\hline$\% 1 \ldots$ & 0 & - & - & - & - & $r \cdot$ & تلقاسيت دورات تندريية في استخدام & 1 & 11 \\
\hline$\% 1 \ldots$ & 0 & - & - & - & - & $r$. & يوجلية إدارة أو قسم للحاسوب في ادارة & 1 & $r$. \\
\hline$\% 1 \ldots$ & 0 & - & - & - & - & r. & 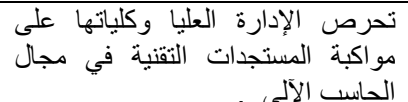 & 1 & TA \\
\hline$\% 97$ & §.^ & - & - & - & $\varepsilon$ & 17 & يوجند ربط بين شبكة الكلية و شبكة & r & 1. \\
\hline$\%$ ^० & \&.YO & - & - & - & 10 & 0 & 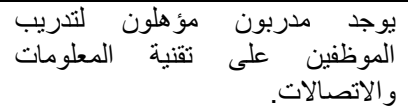 & $r$ & 17 \\
\hline$\% \wedge$ & \&.Yo & - & - & - & 10 & 0 & 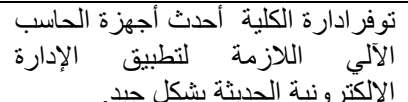 & $r$ & 7 \\
\hline$\% \wedge 0$ & \&.Yo & - & - & - & 10 & 0 & تأهيل العاملين الكلية خطط استخدام تلتريب تواتية & $r$ & $1 \%$ \\
\hline$\%$ ^० & \&.YO & - & - & - & 10 & 0 & 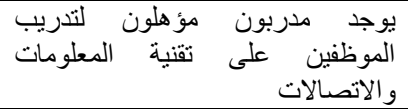 & $r$ & 17 \\
\hline$\%$ ^० & \&.YO & - & - & - & 10 & 0 & تطبيق الإدارة الالكترونية الكيا فيلية سباسة & $r$ & YI \\
\hline$\%$ ^o & E. Yo & - & - & - & 10 & 0 & 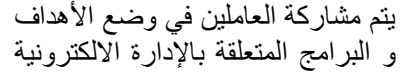 & $r$ & rq \\
\hline$\% \wedge$. & $\varepsilon$ & - & - & - & $r$. & - & 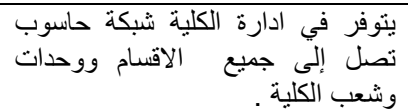 & $\varepsilon$ & $\Lambda$ \\
\hline$\% \wedge$. & $\varepsilon$ & - & - & - & $r$. & - & 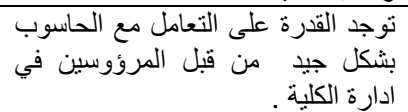 & $\varepsilon$ & $1 \varepsilon$ \\
\hline$\% \wedge$. & $\varepsilon$ & - & - & - & $r$. & - & 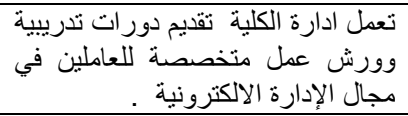 & $\varepsilon$ & YT \\
\hline$\% \wedge$. & $\varepsilon$ & - & - & - & r. & - & 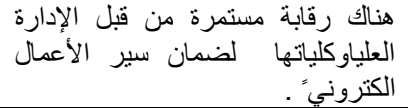 & $\varepsilon$ & $r$. \\
\hline 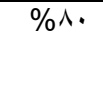 & $\varepsilon$ & - & - & - & r. & - & 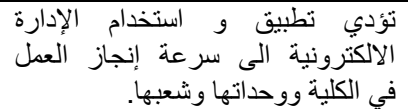 & $\varepsilon$ & Tr \\
\hline$\%{ }^{\wedge}$. & $\varepsilon$ & - & - & - & $r$. & - & 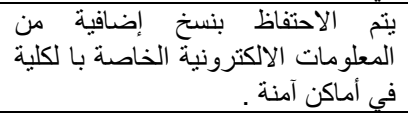 & $\varepsilon$ & $r \varepsilon$ \\
\hline$\% \vee V$ & $\Gamma_{6, \Lambda}$ & - & - & $r$ & TV & - & 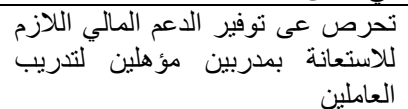 & 0 & $\varepsilon$ \\
\hline$\%$ vo & r.vo & - & - & 0 & 10 & - & 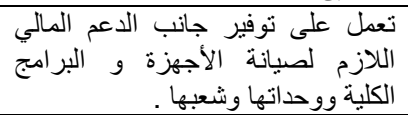 & 7 & $r$ \\
\hline
\end{tabular}


العـدد الرابع والأربعون

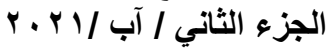

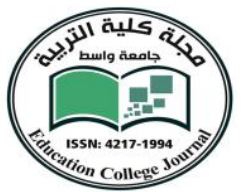

\begin{tabular}{|c|c|c|c|c|c|c|c|c|c|}
\hline$\%$ \%० & r.Vo & - & - & 0 & 10 & - & وفوجد موقع الاخرى على شبكتة الانترنت & 7 & 11 \\
\hline \%४० & r.vo & - & - & 0 & 10 & - & 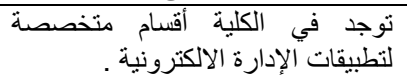 & 7 & YY \\
\hline$\% \vee \varepsilon$ & r.V & - & - & 7 & $1 \varepsilon$ & - & تلتصميم و على توفير البرامج الالكترونية اللادية & V & T \\
\hline$\% \vee Y$ & $r .7$ & - & - & $\lambda$ & $T$ & - & يوجلد خبراء لتصميم و نطوير البرامج & $\wedge$ & IV \\
\hline$\% \vee$. & r.0 & - & - & 1. & 1. & - & 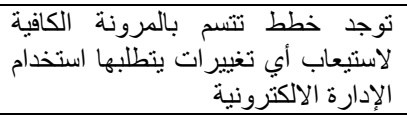 & 9 & $T V$ \\
\hline$\% \vee$. & 5.0 & - & - & 1. & 1. & - & وإسكانية اختراق الإدارة الالكترونة الخاصية بالكلية & 9 & $r \mu$ \\
\hline$\%$ \%० & T.YO & - & 0 & 0 & 1. & - & اللازمة في ادلنبيق الإدارة الالكترونية الموارد البشرية & 1. & 19 \\
\hline$\% 70$ & T.ro & - & 0 & 0 & 1. & - & 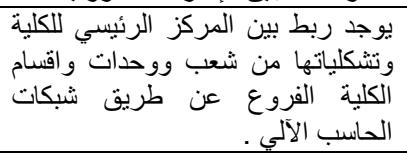 & 1. & 9 \\
\hline$\% 4$. & $r$ & 0 & - & 0 & 1. & - & 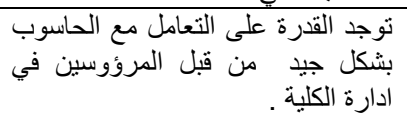 & 11 & V \\
\hline$\%$ \% & $r$ & - & - & $r$. & - & - & 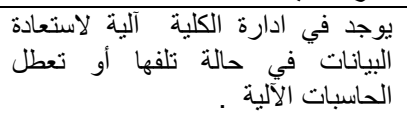 & 11 & ro \\
\hline$\% \circ 1$ & r. 9 & 7 & - & $\varepsilon$ & 1. & - & 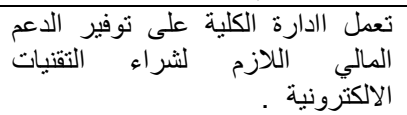 & IT & 1 \\
\hline$\% 0$. & T.O & - & 1. & 1. & - & - & 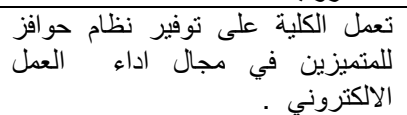 & $1 \pi$ & 0 \\
\hline$\% \leqslant 0$ & Y.YO & 0 & 0 & 1. & - & - & داخل الكتلية . البريد الكتروني في العمل & $1 \varepsilon$ & $T$ \\
\hline$\%$ \& & r..o & $r$ & 10 & $r$ & - & - & تلقاسوبت دورات تدريبية في استخدام & 10 & $r \varepsilon$ \\
\hline$\%$ \% & $1 . \wedge$ & V & 1. & $r$ & - & - & 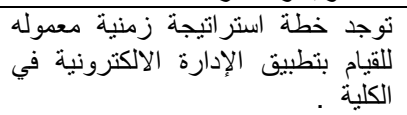 & 17 & $r \mu$ \\
\hline$\%$ \%ч & 1.1 & V & 1. & $r$ & - & - & 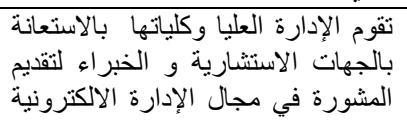 & 17 & r \\
\hline$\% r$. & 1.0 & 1. & 1. & - & - & - & 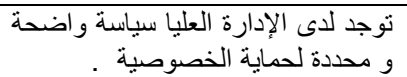 & IV & ro \\
\hline
\end{tabular}




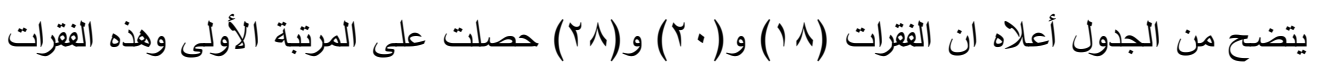
تثير الى وجود بنية تحتية للادارة الاكترونية من حيث التدريب على استخدام الحاسوب والانترنيت ووجود اقسام للحاسوب في كليات الجامعة المستصرية وايضا ان الأدارة العليا في الجامعة تحرص لئه على مواكبة المستجدات التقنية في مجال الحاسوب الالي اما الفقرات التي حصلت على المراتب الاخيرة باقل وسط مرجح من(ب) ووزن منوي أقل من ( •؟\%)

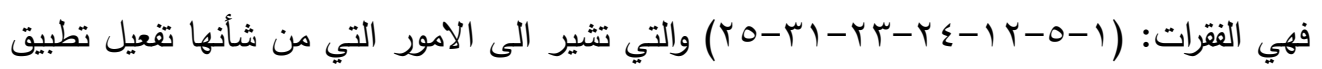
الادارة الاكترونية ففي الفقرة (1) " تعمل الدارة الكلية على توفير الدعم المالي اللازم لشراء التقنيات

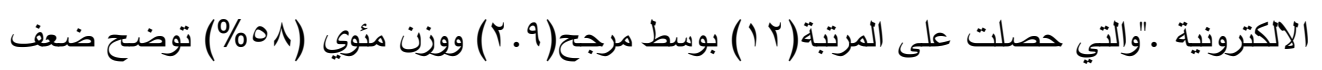
توفير التخصصات المالية لشراء التقنيات الاككترونية والتي بدونها لايمكن تطبيق الادارة الالكترونية أما الفقرة (0)" تعمل الكلية على توفير نظام حوافز للمتميزين في مجال أداء العمل الالكتروني .

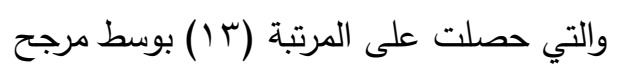
(Y.0) ووزن مئوي ( •0\%) ايضا من باب ضعف توفير التخصصات المالية فلا يوجد نظام الحوافز

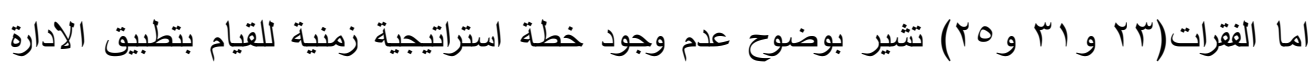
الالكترونية وعدم جلب استثاريين والخبراء من خارج الكلية ايضا لضعف التخصصات المالية .

الهدف الثالث: ما درجة تطبيق الادارة الاكترونية في كليات الجامعة المستنصرية من وجهة نظر

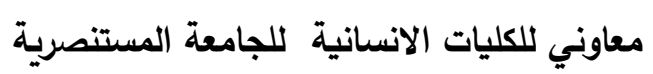
للاجابة عن الهدف الأول تم استخراج المتوسطات المرجحة والوزن المئوي لفقرات الاستبانة كما هو مبين في الجدول (0) المتوسطات المرجحة والوزن المئوي لفقرات الاستبانة من وجهة نظر معاوني كليات الانسانية للجامعة المستتصرية . 
العـدد الرابع والأربعون

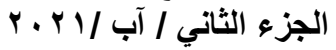
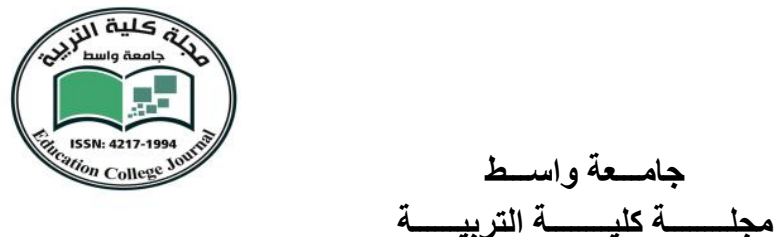

\begin{tabular}{|c|c|c|c|c|c|c|c|c|c|}
\hline 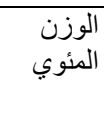 & المرجح & لا لاون & 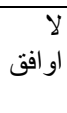 & محايد & اوافق & 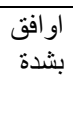 & الفقرة & المرتبة & في \\
\hline$\% 1 \ldots$ & 0 & - & - & - & - & $\Lambda$ & المعلومات والاتي تصالات. متخصصون في تقنية & 1 & 10 \\
\hline$\% 1 \ldots$ & 0 & - & - & - & - & $\Lambda$ & 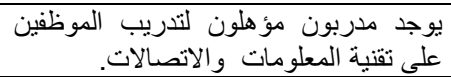 & 1 & 17 \\
\hline$\% 1 \ldots$ & 0 & - & - & - & - & 0 & الكلية . إدارة أو قسم للحاسوب في ادارة & 1 & $r$. \\
\hline$\% 1 \ldots$ & 0 & - & - & - & - & $\Lambda$ & الوادارة في الاكترونية أقسام متخصصة لتطبيقات & 1 & KY \\
\hline$\% 1 \ldots$ & 0 & - & - & - & - & $\Lambda$ & المستجدصات الإدقارة العليا وكلياتها مجال على مواكبة الحاسلي & 1 & $r \wedge$ \\
\hline$\% 94.0$ & E.TYo & - & - & - & $r$ & 0 & 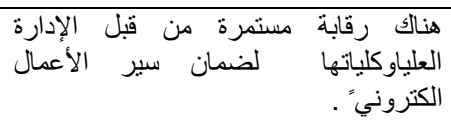 & $r$ & $r$. \\
\hline$\% 9 r .0$ & E.TYo & - & - & - & $r$ & 0 & 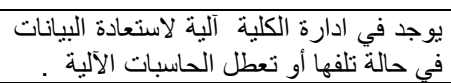 & $r$ & ro \\
\hline$\% \wedge \vee .0$ & $\varepsilon . r v o$ & - & - & - & 0 & $r$ & 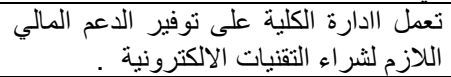 & $r$ & 1 \\
\hline$\% \wedge \vee .0$ & $\varepsilon . r v o$ & - & - & - & 0 & $r$ & 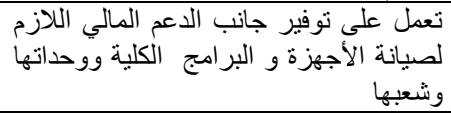 & $r$ & $r$ \\
\hline$\% \wedge \vee .0$ & E.rVo & - & - & - & 0 & $r$ & الالكترونية خبراء لتصميم و تطوير البرامج & $r$ & IV \\
\hline$\% \wedge \vee .0$ & $\varepsilon . r v o$ & - & - & - & 0 & $r$ & تلدعم الإدارة العليا في الكلية سياسة تطبيق & $r$ & YI \\
\hline$\% \wedge \vee .0$ & $\varepsilon . r v o$ & - & - & - & 0 & $r$ & بتطبيق الإدارة الالكترونية فنية الكلية ل معموله للقيام & $r$ & Tr \\
\hline$\% \wedge \vee .0$ & E.rvo & - & - & - & 0 & $r$ & 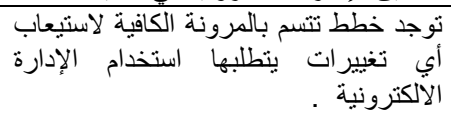 & $r$ & TV \\
\hline$\% \wedge \vee .0$ & $\varepsilon . r v o$ & - & - & - & 0 & $r$ & البرامج مشاركة المتعلقة بالإدارة في الاككترونية الأهداف و . & $r$ & rq \\
\hline$\% \wedge \vee .0$ & $\varepsilon$. rVo & - & - & - & 0 & $r$ & الختراق الموام الإدارة الخاصكترونية بالكلية لعدم إمكانية & $r$ & Tr \\
\hline$\% \wedge 0$ & S.Yo & - & - & - & 7 & $r$ & 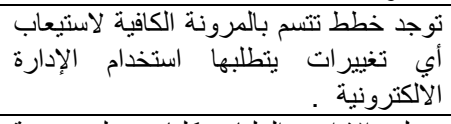 & $\varepsilon$ & TV \\
\hline$\% \wedge$ ․o & $\varepsilon .1$ To & - & - & - & $\mathrm{V}$ & 1 & 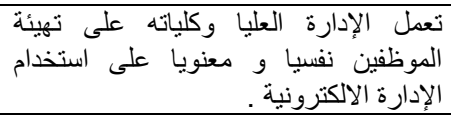 & 0 & $T \varepsilon$ \\
\hline$\% \wedge r .0$ & E.1Yo & - & - & - & $\mathrm{V}$ & 1 & تعمل ادارة الكلية تقديم دورة للعاملين في مجات تدريبية & 0 & YT \\
\hline$\% \wedge$. & $\varepsilon$ & - & - & - & $\Lambda$ & - & للحرصتعانة بمدربين مؤ هلين لتندريب اللعاملين اللازم & 7 & $\varepsilon$ \\
\hline
\end{tabular}


العـدـد الرابع والأربعون

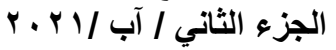

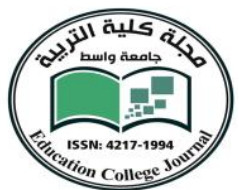

ion College

\begin{tabular}{|c|c|c|c|c|c|c|c|c|c|}
\hline$\% \wedge$. & $\varepsilon$ & - & - & - & 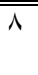 & - & 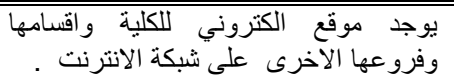 & 7 & 11 \\
\hline$\% \wedge$. & $\varepsilon$ & - & - & - & $\wedge$ & - & 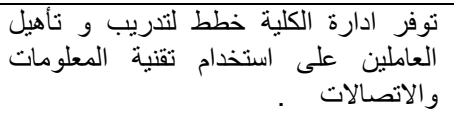 & 7 & 11 \\
\hline$\% \wedge$. & $\varepsilon$ & - & - & - & $\wedge$ & - & 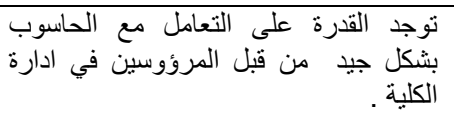 & 7 & $1 \varepsilon$ \\
\hline$\% \wedge$. & $\varepsilon$ & - & - & - & $\wedge$ & - & و تلقيت دورات تلدريبية في استخدام الحاسوب & 7 & 11 \\
\hline$\% \wedge$. & $\varepsilon$ & - & - & - & $\Lambda$ & - & 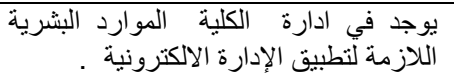 & 7 & 19 \\
\hline$\% \wedge$. & $\varepsilon$ & - & - & - & $\wedge$ & - & 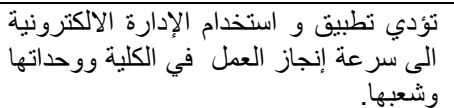 & 7 & Tr \\
\hline$\% \vee r .0$ & r. & - & - & $r$ & 0 & - & 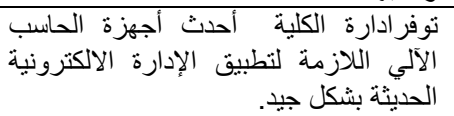 & $V$ & 7 \\
\hline$\% \vee r .0$ & r.To & - & - & $r$ & 0 & - & 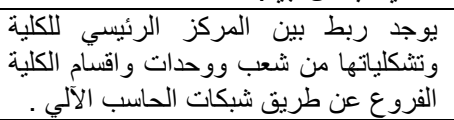 & $V$ & 9 \\
\hline$\% \vee Y .0$ & r. & - & - & $r$ & 0 & - & الانترند ربط بين شبكة الكلية و شبكة & $V$ & 1. \\
\hline$\% \vee Y .0$ & r. & - & - & $\mu$ & 0 & - & يتم استخدام البريد الكتروني في العمل داخل & $V$ & Ir \\
\hline$\% \vee r .0$ & r. Tro & - & - & $r$ & 0 & - & توجد للى الإدارة العليا سباسة واضحة و و لحمدية & $V$ & ro \\
\hline$\% \vee r .0$ & r. & - & - & $r$ & 0 & - & 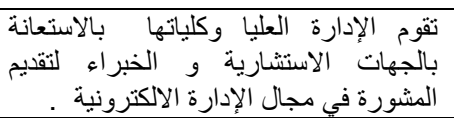 & $V$ & M \\
\hline$\% \vee$. & r.o & - & - & $\varepsilon$ & $\varepsilon$ & - & الثتوفر أحدث النظم والبرامج الإكثرونية الحدة لتطبيث & $\Lambda$ & $\mathrm{V}$ \\
\hline$\% \vee$. & r.o & - & - & $\varepsilon$ & $\varepsilon$ & - & 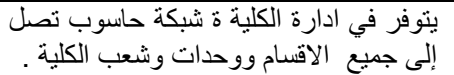 & $\Lambda$ & $\Lambda$ \\
\hline$\% 7 V .0$ & T.Mo & - & - & 0 & $r$ & - & 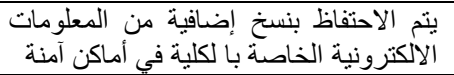 & 9 & $T \varepsilon$ \\
\hline$\% \leqslant V .0$ & r.rVo & - & 0 & $r$ & - & - & 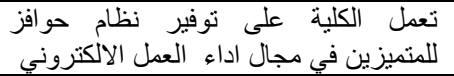 & 1. & 0 \\
\hline$\% \leq 0$ & r. YO & $\varepsilon$ & - & $r$ & $r$ & - & 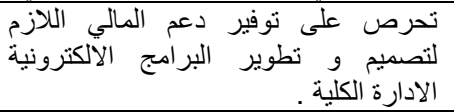 & 11 & $r$ \\
\hline
\end{tabular}




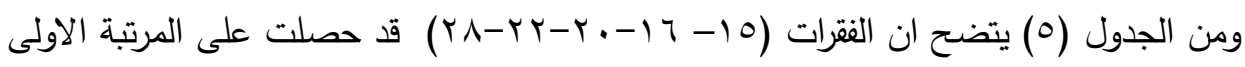
بوسط مرجح (0) ووزن مئوي ( . (1\%) وهي ايضا كما ذكرنا بنية تحتية للادارة الالكترونية مثل مضمون الفقرة (10) " يوجد في الكلية متخصصون في تقنية المعلومات والا تصالات. " والفقرة

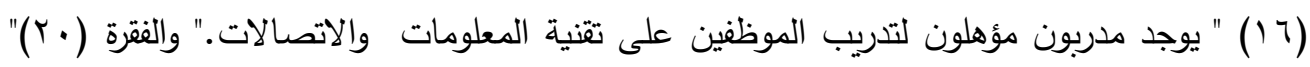
يوجد إدارة أو قسم للحاسوب في ادارة الكلية ." وهكذا بقيية الفقرات اما الفقرات التي لم تحصل على متوسط مرجح اقل من(ب) ووزن مئوي ( • ج\%) فهي فقرتان

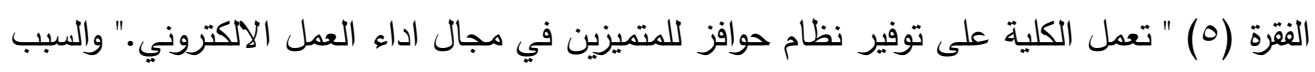
عدم وجود تخصيصات مالية والفقرة الثانية فقرة (r) " تحرص على توفير دعم المالي اللازم لتصميم و تطوير البرامج الاكترونية الادارة الكلية ." ايضا لعدم توفر مخصصات مالية في الجامعة

الهدف الرابع: ما درجة تطبيق الادارة الالكترونية في كليات الجامعة المستصرية من وجهة نظر

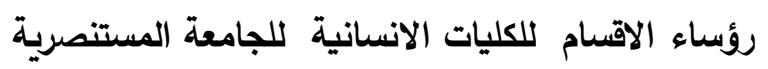
للاجابة عن الهدف الاول تم استخراج المتوسطات المرجحة والوزن المئوي لفقرات الاستبانة كما هو مبين في الجدول (7) المتوسطات المرجحة والوزن المئوي لفقرات الاستبانة من وجهة نظر رؤساء الاقسام لكليات الانسانية للجامعة المستتصرية

\begin{tabular}{|c|c|c|c|c|c|c|c|c|c|}
\hline الوئوي & المرجح & باو الافن & 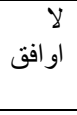 & محايد & اواوفق & بشدة اوق & الفقرة & المرتبة & الاستبانة في \\
\hline$\% q r$ & $\varepsilon .7$ & - & - & - & 1. & 10 & 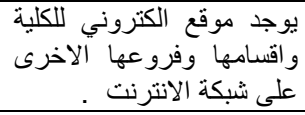 & 1 & 11 \\
\hline$\% q 4$ & $\varepsilon .7$ & - & - & - & 1. & 10 & 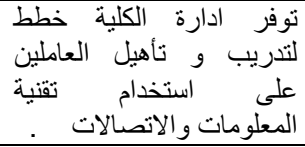 & 1 & 14 \\
\hline$\% q r$ & $\varepsilon .7$ & - & - & - & 1. & 10 & 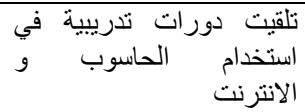 & 1 & 11 \\
\hline$\% q r$ & $\varepsilon .7$ & - & - & - & 1. & 10 & 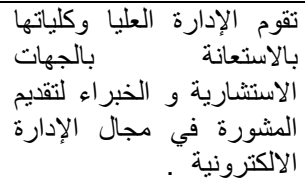 & 1 & TI \\
\hline$\% \wedge \wedge$ & $\varepsilon . \varepsilon$ & - & - & - & 10 & 1. & 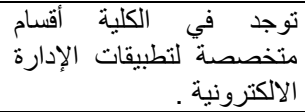 & $r$ & YY \\
\hline
\end{tabular}




\begin{tabular}{|c|c|c|c|c|c|c|c|c|c|}
\hline$\% \wedge \wedge$ & $\overline{\varepsilon \varepsilon}$ & - & - & - & 10 & 1. & 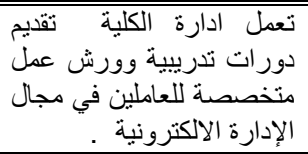 & $\overline{T r}$ & $\overline{r y}$ \\
\hline$\% \wedge \wedge$ & $\varepsilon . \varepsilon$ & - & - & - & 10 & 1. & الإدارة ت تطبيث الالكثرونية و الكتخدام & $r$ & Tr \\
\hline$\% \wedge \wedge$ & $\varepsilon . \varepsilon$ & - & - & - & 10 & 1. & 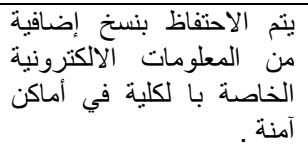 & $r$ & Ts \\
\hline$\% \wedge \varepsilon$ & $\varepsilon . Y$ & - & - & - & r. & 0 & الحاسو القدرة على التعامل مب من قبل & $r$ & $1 \varepsilon$ \\
\hline$\% \wedge \varepsilon$ & $\varepsilon . Y$ & - & - & - & r. & 0 & 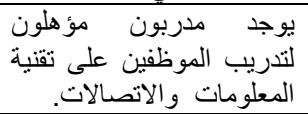 & $r$ & 17 \\
\hline$\% \wedge \varepsilon$ & $\varepsilon . Y$ & - & - & - & $r$. & 0 & 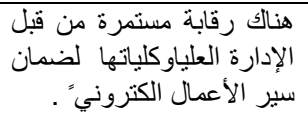 & $r$ & $r$. \\
\hline$\% \wedge 1.7$ & $\varepsilon . \wedge$ & - & - & $r$ & IV & 0 & 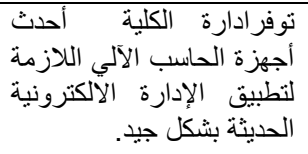 & $\varepsilon$ & 7 \\
\hline$\% \wedge$. & $\varepsilon$ & - & - & 0 & 10 & 0 & و شوجد ربط الانترنت بين شبكة الكلية & 0 & 1 . \\
\hline$\% \vee 7$ & $r . \wedge$ & - & - & 0 & $r$. & - & 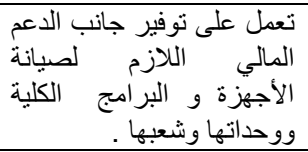 & 7 & $r$ \\
\hline$\% \vee 7$ & $\Gamma . \wedge$ & - & - & 0 & $r$. & - & في تصني في الكلية متخصصون المعلومات والان & 7 & 10 \\
\hline$\% \vee 7$ & $r . \wedge$ & - & - & 0 & $r$. & - & تطوجير البرامج الالكترونية لتصمية و & 7 & IV \\
\hline$\% \vee 7$ & $r . \wedge$ & - & - & 1. & 1. & 0 & 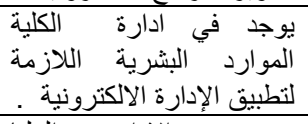 & 7 & 19 \\
\hline$\% \vee 7$ & $\Gamma . \wedge$ & - & - & - & 10 & 1. & 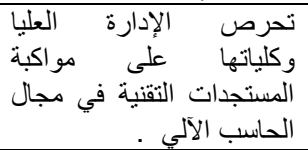 & 7 & $r \wedge$ \\
\hline$\% \vee r$ & T.7 & - & - & 1. & 10 & - & 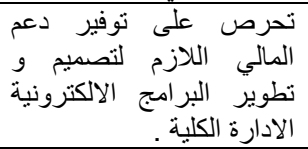 & V & Y \\
\hline$\% \vee r$ & $r .7$ & - & - & 1. & 10 & - & 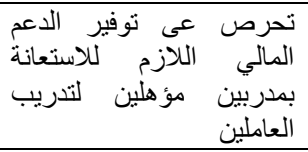 & V & $\varepsilon$ \\
\hline
\end{tabular}


العـدد الرابع والأربعون

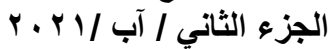

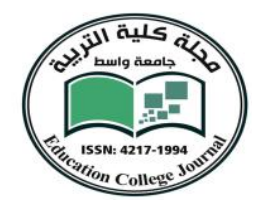

ation College

\begin{tabular}{|c|c|c|c|c|c|c|c|c|c|}
\hline \%VY & "ז.7 & - & - & 1. & 10 & - & اللتوفرمة أحدث لتطبيق النظم والبرامجة الإدارة & $\overline{~ V ~}$ & $\overline{\bar{V}}$ \\
\hline$\% \vee r$ & $r .7$ & - & - & 1. & 10 & - & في العمل داخل البكلية الكتروني & V & IY \\
\hline$\% \vee r$ & $r .7$ & - & - & 1. & 10 & - & للحاسدوب في إدارة الكلية . قسم & V & $r$. \\
\hline$\% \vee r$ & $r .7$ & - & - & 1. & 10 & - & 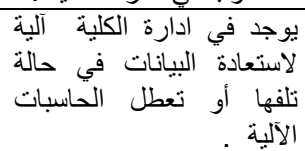 & V & $r_{0}$ \\
\hline$\% \curlyvee 1$ & r. & - & - & 10 & 1. & - & 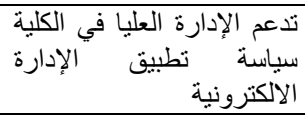 & $\Lambda$ & $r$ \\
\hline$\% т \varepsilon$ & $r . r$ & - & 0 & 1. & 1. & - & 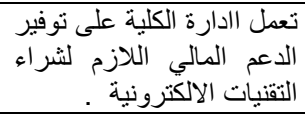 & 9 & $T$ \\
\hline 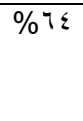 & $r . r$ & - & 0 & 1. & 1. & - & ولتمع مشاركة الأهداف و والبالين امجي & 9 & $r q$ \\
\hline$\% 4$. & $\Gamma$ & 0 & - & 1. & 1. & - & 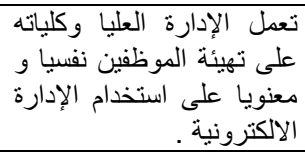 & 1. & $r \varepsilon$ \\
\hline$\% 4$. & $r$ & 1. & - & 0 & 1. & - & 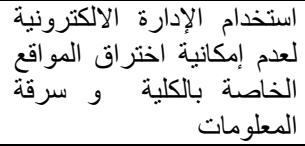 & 1. & $r r$ \\
\hline$\% 07$ & r.A & 0 & 0 & 0 & 1. & - & توعموله للقيام استطراتيجة الإدارة زمنية & 11 & $r r$ \\
\hline$\% 07$ & r.1 & - & 1. & 1. & 0 & - & و شبكة ربطن بين شبكة الكلية & 11 & $T V$ \\
\hline \%or & T.T & 0 & 0 & 0 & 1. & - & 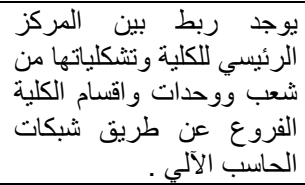 & IT & 9 \\
\hline$\%$ \& & T.Y & 0 & 1. & 1. & - & - & 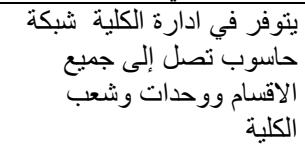 & 14 & $\lambda$ \\
\hline$\% \leq \leqslant$ & T.Y & 。 & 1. & 1. & - & - & 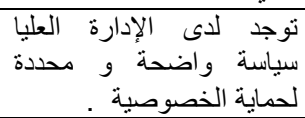 & 14 & ro \\
\hline$\% \curlyvee \wedge$ & $1 . \varepsilon$ & 10 & 1. & - & - & - & 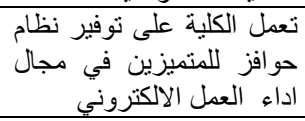 & $1 \varepsilon$ & 0 \\
\hline
\end{tabular}




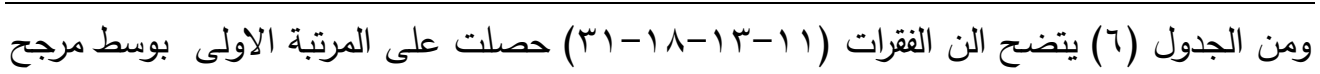
(T.؟) ووزن مئوي (r9\%) من وجهة نظر رؤساء الاقسام للكليات الانسانية وهي كما ذكرنا انفا وجود البنية التحتية لتطبيق الادارة الالكترونية

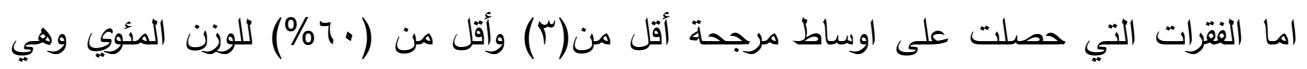

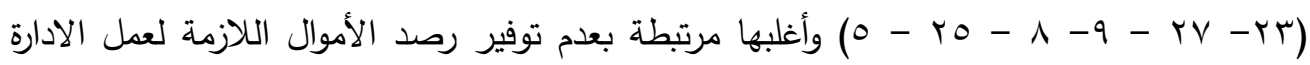
الاكترونية

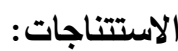

ا. تبين بان هناك ضعف كبير في أساسيات الادارة الاككترونية ووجود حاسبة الام التي تسيطر على كل حاسبات الكلية

r. تبين من نتائج ضعف استخدام البريد الكتروني في العمل داخل الكلية خارج الكلية.

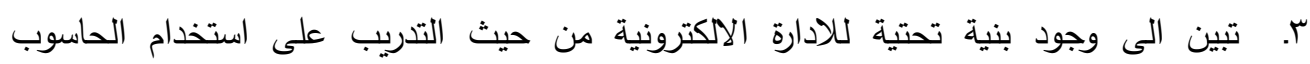

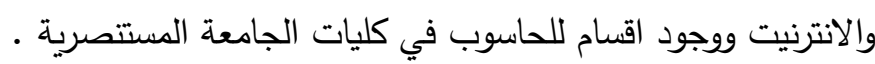
ع. ان الادارة العليا في الجامعة تحرص على مواكبة المستجدات التقنية الازمة والبرامج الالكترونية واحدث النظم في مجال الحاسوب الادلي. ه . تضح من النتائج وجود ضعف في توال توفير نظام حوافز للمتميزين في مجال اداء العمل الاككتروني

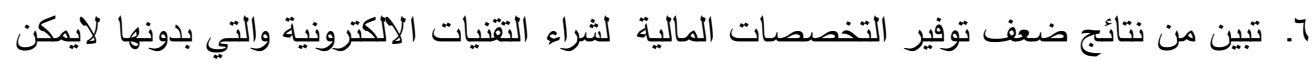
تطبيق الادارة الالكترونية.

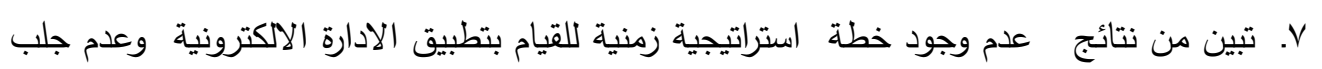

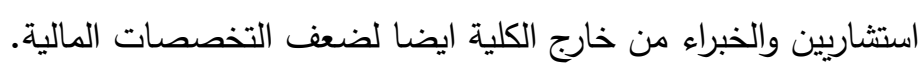

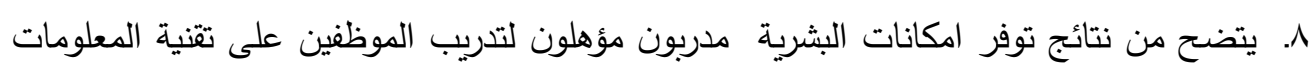

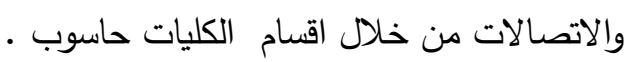


ا. العمل على دعم التخصيص المالي اللا زم لتوفير متطلبات احتياجات الكلية . r. العمل على وضع نظام حوافز جيد اشخاص المتميزين في مجال العمل اداء الكتروني.

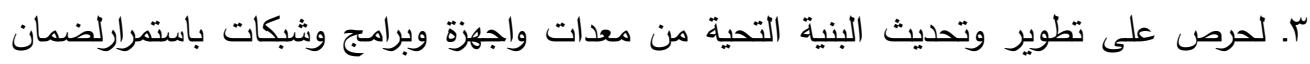

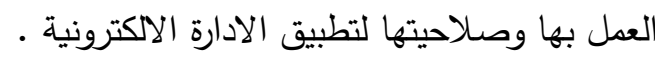

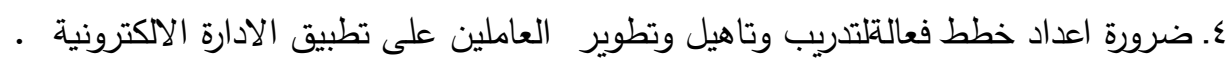

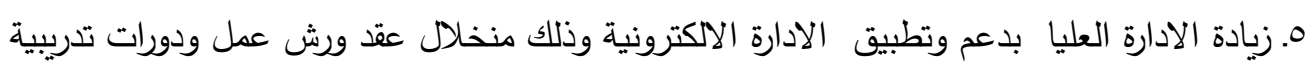
وندوات العلمية النشر الثقافة العمل بها آ. العمل على استعانة بالمتخصصين والخبراء لتقديم الاستثارات في مجال تطبيق الادارة الالكترونية V. ضرورة الاهتمام بخطةاستراتيجية زمنية لضمان تطبيق الادارة الا لكترونية.

\section{المقترحات :}

ا. اجراء دارسة مماثلة مستوى تطبيق الادارة الكترونية في كليات الجامعة المستتصرية من وجهة نظر

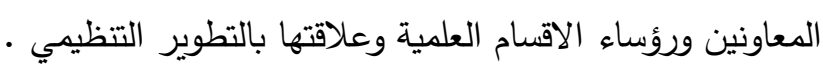

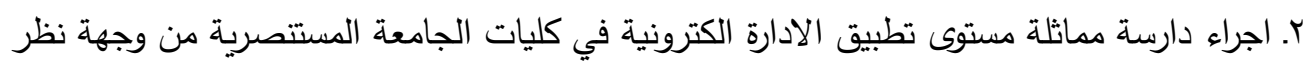

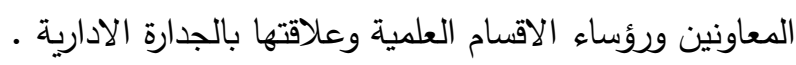

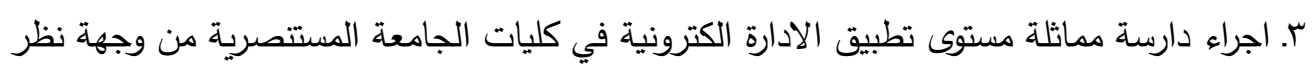

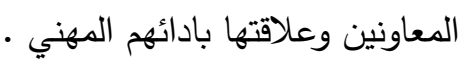


1- عمار، حمح جمال اكرم(9 . . ץ) : مدى امكانية تطبيق الادارة الاكترونية بوكالة غوث وتشغيل اللاجئين بمكتب غزة الإقليمي ودورها في تحسين اداء العاملين ، رسالة ماجستير عير منشورة الجامعة الاسلامية -غزة.

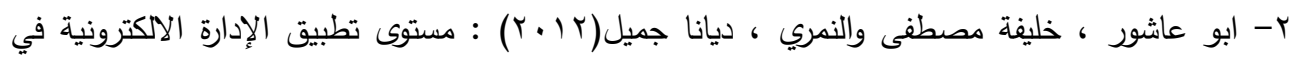
جامعة اليرموك من وجهة نظر الهيئة التدريسية والإداريين ، المجلة الاردنية في العلوم التربوية - مجلد 9 عدد r . r- اسماعيل ، هادي خليل و عباس، سعد فاضل ( 17 (ب) مستوى تطبيق وظائف الادارة الالكترونية في

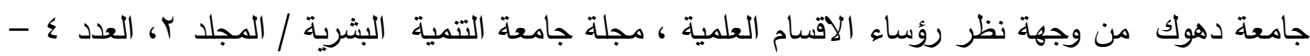
كانون الاول . كامعه دهو

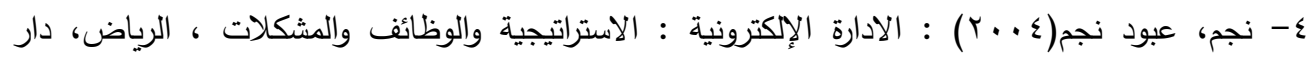
الثروق.

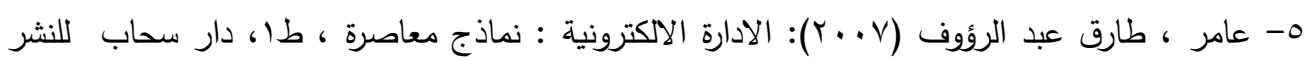
والتوزيع ، القاهرة.

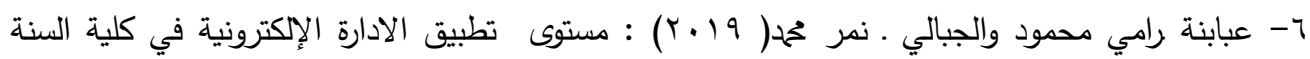

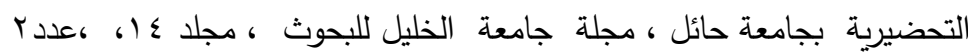

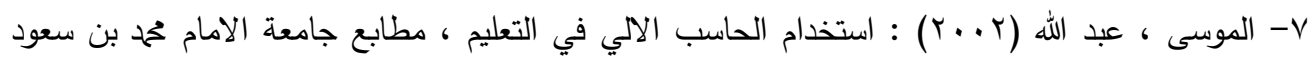
الاسلامية ، الرياض.

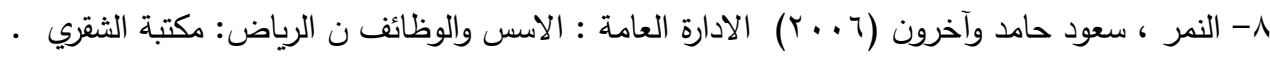

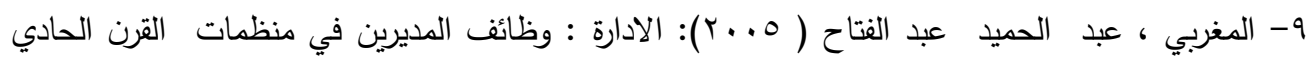

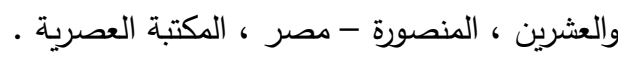

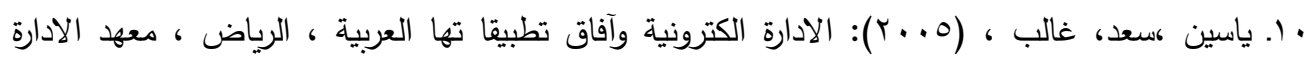
العامة مركزالبحوث. 1ا. رشوان ، رأفت ،(ع . . r ) :الادارة الكترونية ،القاهرة، مركز المعلومات ، ودعم اتخاذ القرار ، بمجلس الوزاراء.

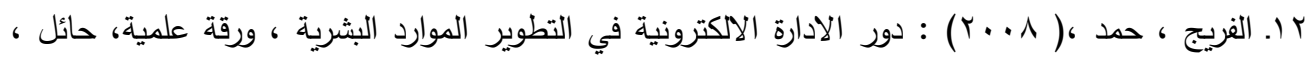
مجلة البحوث التربوية. 
العـدا الرابع والأربعون

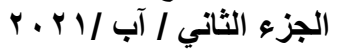

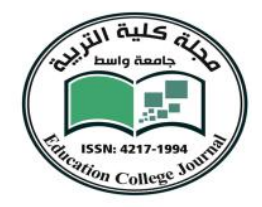

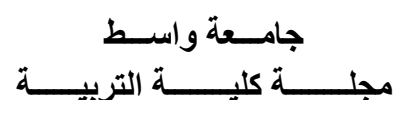

13.Taher, A. (2010). Electronic management between theory and practice. Amman: Dar Al-Raya Publishing House.

14-Berri, A. (2005). Applications of electronic administration in system operations. Alexandria: Dar Al Ma'a ref.

15 .Al-Salmi, A. (2006). Electronic management. Amman: Weal Publishing House 13- Alalak, B. \& Wissen, S. (2006). Electronic Management. Amman: Curriculum House for Publishing 